\title{
Transitions of protein traffic from cardiac ER to junctional SR
}

\author{
Naama H. Sleiman, Ph.D. ${ }^{1}$, Timothy P. McFarland, Ph.D. ${ }^{1}$, Larry R. Jones, M.D., Ph.D. ${ }^{2}$, and \\ Steven E. Cala, Ph.D. ${ }^{1}$ \\ ${ }^{1}$ Department of Physiology, School of Medicine Wayne State University, Detroit, MI 48201
}

${ }^{2}$ Krannert Institute of Cardiology, Indiana University, Indianapolis, IN 46202

\begin{abstract}
The junctional sarcoplasmic reticulum (jSR) is an important and unique ER subdomain in the adult myocyte that concentrates resident proteins to regulate $\mathrm{Ca}^{2+}$ release. To investigate cellular mechanisms for sorting and trafficking proteins to jSR, we overexpressed canine forms of junctin (JCT) or triadin (TRD) in adult rat cardiomyocytes. Protein accumulation over time was visualized by confocal fluorescence microscopy using species-specific antibodies. Newly synthesized $\mathrm{JCT}_{\mathrm{dog}}$ and $\mathrm{TRD}_{\mathrm{dog}}$ appeared by $12-24 \mathrm{~h}$ as bright fluorescent puncta close to the nuclear surface, decreasing in intensity with increasing radial distance. With increasing time (24-48 h), fluorescent puncta appeared at further radial distances from the nuclear surface, eventually populating jSR similar to steady-state patterns. CSQ2-DsRed, a form of CSQ that polymerizes ectopically in rough ER, prevented anterograde traffic of newly made $\mathrm{TRD}_{\operatorname{dog}}$ and $\mathrm{JCT}_{\text {dog }}$, demonstrating common pathways of intracellular trafficking as well as in situ binding to CSQ2 in juxtanuclear rough ER. Reversal of CSQD-sRed interactions occurred when a form of TRD $\mathrm{dog}_{\text {gas }}$ wsed in which CSQ2-binding sites are removed ( ${ }^{\mathrm{del}} \mathrm{TRD}$ ). With increasing levels of expression, CSQ2DsRed revealed a novel smooth ER network that surrounds nuclei and connects the nuclear axis. $\mathrm{TRD}_{\text {dog }}$ was retained in smooth ER by binding to CSQ2-DsRed, but escaped to populate jSR puncta. $T R D_{\text {dog }}$ and del TRD were therefore able to elucidate areas of ER-SR transition. High levels of CSQ2-DsRed in the ER led to loss of jSR puncta labeling, suggesting a plasticity of ERSR transition sites. We propose a model of ER and SR protein traffic along microtubules, with prominent transverse/radial ER trafficking of JCT and TRD along Z-lines to populate jSR, and an abundant longitudinal/axial smooth ER between and encircling myonuclei, from which jSR proteins traffic.
\end{abstract}

\section{Keywords}

triadin; junctin; junctional sarcoplasmic reticulum; rough ER; smooth ER

\section{(C) 2015 Published by Elsevier Ltd.}

Correspondence should be addressed to: Steven Cala, Ph.D. Department of Physiology Wayne State University Detroit, MI, USA 48201 Tel.: 313-577-8734 s.cala@wayne.edu.

Publisher's Disclaimer: This is a PDF file of an unedited manuscript that has been accepted for publication. As a service to our customers we are providing this early version of the manuscript. The manuscript will undergo copyediting, typesetting, and review of the resulting proof before it is published in its final citable form. Please note that during the production process errors may be discovered which could affect the content, and all legal disclaimers that apply to the journal pertain.

Disclosures: None declared. 


\section{Introduction}

The cardiac secretory pathway is a network of inner membranes that serves a range of functions through a continuous set of functional membrane subdomains. In the adult cardiomyocyte, the endoplasmic and sarcoplasmic reticulum (ER/SR) stretch across the sarcomeres of the myocyte forming critical subdomains that regulate $\mathrm{Ca}^{2+}$ homeostasis [1-5]. Many functional processes in the heart rely upon the orchestrated movements of $\mathrm{Ca}^{2+}$ and the resident proteins of multiple SR and sarcolemmal subcompartments. In all cells, resident ER/SR proteins are synthesized within a rough ER subdomain, then traffic to more distal sites either by diffusion or targeting, but these established biosynthetic steps remain poorly understood within the context of the myocyte.

Two major functional subdomains of the SR are recognized in cardiac myocytes [1, 6-9]. $\mathrm{Ca}^{2+}$ release is regulated by SR interactions with sarcolemma and transverse (T)-tubules. Junctional SR (jSR) concentrates a few prominent resident proteins, such as the $\mathrm{Ca}^{2+}$-release channel, ryanodine receptor (RYR2) [3, 8, 10, 11], calsequestrin (CSQ2) [8, 12], a luminal resident protein, and two small transmembrane proteins, triadin (TRD) [13-15] and junctin (JCT) [16], that bind CSQ2 in vitro [15].

The second major site of $\mathrm{SR} \mathrm{Ca}^{2+}$-handling function is a subdomain more specialized to remove $\mathrm{Ca}^{2+}$ from the cytoplasm due to its high levels of the SR/ER $\mathrm{Ca}^{2+}$-ATPase (SERCA2) [8, 17]. SERCA2 protein levels are high across the SR membrane system, but with relatively reduced levels close to jSR sites $[8,17]$. SERCA2 localization may best be described morphologically as present everywhere except non-jSR, as opposed to residing in longitudinal SR $[8,17]$. Thus, morphological relationships between these two cardiac domains are defined primarily by their functions, not by cell biological biogenesis and trafficking.

We previously reported that CSQ2, when fused to the fluorescent protein DsRed, polymerizes inside early compartments of cardiac ER/SR producing a bright red fluorescence around nuclei that co-localizes with rough ER markers [18]. Double labeling of the polymeric and monomeric forms of CSQ2-DsRed suggested that CSQ2 is selectively retained because of its polymerization state [18], consistent with the discrete localizations of CSQ1 and CSQ2 in nonmuscle cells [19, 20]. CSQ2 immunoreactivity elucidates welldefined polygonal ER tubules characteristic of the organelle [19], while, CSQ1, because it does not polymerize in the ER, populates the "next" organelle (distally) - the ER-Golgi intermediate compartment (ERGIC) [20]. Trafficking of these ER tubules containing polymerized CSQs clearly occurs along microtubules (MTs), and MT disruption by nocodazole results in scattered patches of ER throughout the cytosol. In cultured cardiomyocytes, the jSR appears to is a dynamic structure in which resident proteins such as ryanodine receptor-containing ER exhibit ongoing ER movement that is sensitive to inhibition of MT motor proteins dynein and kinesin [21].

To reveal early trafficking steps of jSR proteins, we carried out immunofluorescence analyses of acutely expressed transmembrane proteins $\mathrm{JCT}_{\mathrm{dog}}$ and $\mathrm{TRD}_{\mathrm{dog}}$. Junctional SR proteins were synthesized in rough ER juxtaposed to the nucleus, and with time filled ER 
both axially and radially along MTs, although population of jSR was primarily along radial (transverse) ER tubules.

\section{Materials and Methods}

\subsection{Heart cell preparation and culture}

The investigation conforms to the Guide for the Care and Use of Laboratory Animals published by the US National Institutes of Health (NIH Publication No. 85-23, revised 1996). Animal research was approved by the Wayne State University Animal Investigation Committee (protocol \#A 04-02-13). Cells were prepared as previously described [22]. Briefly, hearts of male Sprague-Dawley rats were excised and perfused by Langendorff method. Enzymatic dissociation was carried in $5 \mathrm{mg}$ Liberase Blendzyme (Roche) in Hank's buffer at $37^{\circ} \mathrm{C}$. Cells were resuspended in Medium 199 containing $2 \%$ bovine serum albumin, $2 \mathrm{mM}$ carnitine, $5 \mathrm{mM}$ creatine, $5 \mathrm{mM}$ taurine, $2 \mathrm{mM}$ L-glutamine, $2 \mathrm{mM}$ Glutamax-1 (Invitrogen), ITS mixture (Sigma I3146), 100 units $/ \mathrm{ml}$ penicillin G, $0.1 \mathrm{mg} / \mathrm{ml}$ streptomycin and $25 \mu \mathrm{M}$ blebbistatin [22] were plated on laminin-coated dishes at $37{ }^{\circ} \mathrm{C}$ with $5 \% \mathrm{CO}_{2}$.

\subsection{Adenoviral-mediated expression}

Adenoviruses encoding CSQ-DsRed (Ad.CSQ-DsRed) and TRD $\operatorname{dog}$ (Ad.TRD) were previously described [23, 24]. Ad.JCT was constructed from the canine cDNA [16, 25] As previously described [18], adenoviruses were added directly to dishes $2 \mathrm{~h}$ post-plating. Treatments were carried out for 12 or 16, 24, and $48 \mathrm{~h}$ before harvesting for biochemical analysis and fixing of coverslips for microscopy.

\subsection{Antibodies}

Monoclonal anti-JCTdog 5D8 (epitope: residues 156-154) and anti-TRD $\mathrm{dog}_{\mathrm{d}} 8 \mathrm{G} 5$ (epitope: residues: 125-132) antibodies, raised towards purified canine JCT and canine TRD [14, 26], were generated by standard mouse monoclonal technology, and epitopes determined using Pepspot, JTP Peptide. Canine TRD-specific rabbit polyclonal antibodies raised to the Cterminus of canine cardiac TRD were previously described [24]. Mouse anti-a-tubulin antibodies was Sigma T6074 and rabbit anti-BIII-tubulin was Abcam ab52901. Mouse monoclonal anti-rat TRD antibodies were from Thermo (MA3-927). Alexa Fluor 488 or 568 conjugated goat anti-rabbit IgG, Alexa Fluor 488 or 568-conjugated goat anti-mouse IgG secondary antibodies were purchased from Invitrogen. Relative specificity/selectivity of the antibodies used towards dog or rat jSR proteins indicated by (+) or (-) are shown in Table I.

\subsection{Immunoblotting}

SDS-PAGE was carried out according to Laemmli [27] on $10 \%$ acrylamide gels or using Invitrogen 10\% Bis-Tris MIDI gels as indicated. Gels were transferred to nitrocellulose membranes $(0.45 \mu \mathrm{m}$, Bio-Rad Laboratories) and stained with Amido black (Sigma). Immunoblotting was carried out as previously described [22] using HRP-conjugated secondary antibodies (Jackson ImmunoResearch Laboratories) and enhanced chemiluminescence (Thermo Scientific), visualized by autoradiography (Amersham 
Hyperfilm ECL film, GE Healthcare). Protein concentrations were determined according to Lowry [23].

\subsection{Fluorescence microscopy}

Preparation of slides for microscopy was as previously described [18]. Briefly, cells were fixed on coverslips with 4\% paraformaldehyde in PBS for $15 \mathrm{~min}$ and then permeabilized for $10 \mathrm{~min}$ in $0.2 \%$ Tween-20. Coverslips were blocked in PBS with $0.2 \%$ Tween-20 (PBS/ Tween) and $2 \%$ goat serum at room temperature for $20 \mathrm{~min}$. Cells were then incubated in PBS/Tween with primary antibody $(1: 100)$ overnight at $4{ }^{\circ} \mathrm{C}$, followed by washing in PBS/ Tween, and incubation with goat anti-rabbit IgG or goat anti-mouse IgG antibodies conjugated to Alexa Fluor dyes (1:100 dilution in PBS/Tween for $120 \mathrm{~min}$ ). Cells were counterstained with NucBlue Fixed Cell ReadyProbes Reagent (Molecular probes R37606) for $30 \mathrm{~min}$. rinsed, and mounted to microscope slides with ProLong Antifade Mounting Kit (Molecular Probes). Imaging was performed using a $63 \times / 1.4$ oil objective on a Leica Advanced Fluorescence system (AF6000). Confocal images were processed and optimized offline for publication using Photoshop (Adobe Systems Inc.). Fluorescence intensity quantification was performed using ImageJ (Wayne Rasband, National Institutes of Health). Images were obtained as a series of optical slices (Z-stack), and single confocal images were selected for quantitation. Transverse lines of approximately 100 pixels were used to select areas within confocal planes that extended from the edge of one nucleus to the cell edge. Channel values were standardized for plotting using Microsoft Excel. Fluorescence intensity analyses were performed on images taken using identical camera settings for a given antibody without offline adjustments.

\section{Results}

\subsection{Specie-specific antibodies to jSR proteins}

Immunoreactivities of antibodies were tested against canine and rat heart samples. Anti-

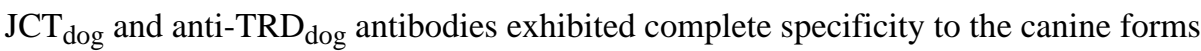
(Table I and Fig. 1). These antibodies would therefore permit the specific detection of acutely expressed canine JCT and TRD above steady-state levels of the native rat heart protein forms. Meanwhile, rat forms $\mathrm{JCT}_{\text {rat }}$ and $\mathrm{TRD}_{\text {rat }}$ were detected using a second set of antibodies, although anti-JCT $\mathrm{T}_{\text {rat }}$ detected both forms. The anti-TRD $\mathrm{Trat}_{\text {antibody detected a }}$ single immunoreactive band of roughly $50 \mathrm{kDa}$ (Fig. 1B). The reason for this aberrant mobility compared to the canine form was not further investigated.

\subsection{Early accumulation of overexpressed $\mathrm{JCT}_{\mathrm{dog}}$ and $\mathrm{TRD}_{\mathrm{dog}}$ at juxtanuclear sites of jSR}

To visualize intracellular sites of earliest $\mathrm{JCT}_{\operatorname{dog}}$ and $\mathrm{TRD}_{\mathrm{dog}}$ accumulation and early trafficking, we analyzed cultured rat cardiomyocytes after 12, 24, 30 and $48 \mathrm{~h}$ of expression. Confocal images of indirect immunofluorescence were generally acquired as a Z-stack covering the height of the cell in contiguous series of optical slices of $0.5 \mu \mathrm{M}$ thickness, allowing us to most clearly identify the optical planes in which transverse ER/SR structures radiated outward from nuclei. 
$\mathrm{JCT}_{\mathrm{dog}}$ first appeared after 16-24 h of virus treatment, and its early distribution showed a restricted pattern of puncta that surrounded nuclei, when viewed in an optical plane through the center of a nucleus. The most intensely fluorescent puncta were those that most closely encircled the nucleus, starting approximately $1 \mu \mathrm{M}$ from the nuclear surface (Fig. 2A,B). Additional puncta of lower intensity appeared to radiate away from the nuclear surface along transverse (Z-) lines towards the periphery of the cell. $\mathrm{JCT}_{\mathrm{dog}}$ immunofluorescence colocalized with that of native $\mathrm{JCT}_{\text {rat }}$, validating its passage across, and concentration in jSR. With increasing incubation times, $\mathrm{JCT}_{\mathrm{dog}}$ accumulated in $\mathrm{jSR}$ at greater distances from the nuclear surface, suggesting a peripherally directed movement of protein across the cell. By 36-48 $\mathrm{h}$ of incubation, the distribution of $\mathrm{JCT}_{\mathrm{dog}}$ was qualitatively similar to that of native $\mathrm{JCT}_{\text {rat }}$. Native $\mathrm{JCT}_{\text {rat }}$ could be observed across jSR puncta using anti-JCT $\mathrm{Jat}_{\text {rat }}$ antibodies, but

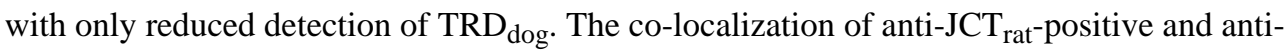
$\mathrm{JCT}_{\mathrm{dog}}$-positive puncta across the cell width, independent of relative immunoreactive strengths, suggested that both were co-localized in the same jSR sites.

To quantitate the overt changes in $\mathrm{JCT}_{\text {dog }}$ distribution near the myonuclei with increasing times in culture after virus treatment, we measured fluorescence intensities, beginning with the most juxtanuclear puncta. The measured changes were consistent with a continuous buildup of protein levels next to the nucleus, leading to a monotonic dissipation across the cell width over $48 \mathrm{~h}$ of expression. The time course of $\mathrm{JCT}_{\mathrm{dog}}$ accumulation observed in the microscope was validated by immunoblotting of harvested cells (Fig. 2D). $\mathrm{JCT}_{\text {dog }}$ levels rose significantly between 24 and $48 \mathrm{~h}$. $\mathrm{TRD}_{\mathrm{dog}}$ showed a pattern of accumulation that was similar to that of $\mathrm{JCT}_{\mathrm{dog}}$, first appearing in cultured cardiomyocytes around $16-24 \mathrm{~h}$ in culture (Fig. 3). TRD $D_{\text {dog }}$ and $\mathrm{TRD}_{\text {rat }}$ immunofluorescence co-localized with similar distributions, suggesting a direct passage of newly made JCT and TRD across, and concentration in, jSR (Fig. 3B,C).

\subsection{In-situ interaction of $\mathrm{JCT}_{\text {dog }}$ and $\mathrm{TRD}_{\text {dog }}$ with juxtanuclear CSQ2-DsRed in rough ER}

Newly synthesized $\mathrm{JCT}_{\mathrm{dog}}$ or $\mathrm{TRD}_{\mathrm{dog}}$ formed puncta beginning a short distance $(\sim 1 \mu \mathrm{M})$ from the nuclear surface. Lower but detectable levels of protein were often observed closer to the nuclear surface at early times (cf. Fig. 4B, white arrowheads), suggesting that the initial highly fluorescent jSR puncta were yet distal to the actual sites of biosynthesis. To further investigate the sites of jSR protein biosynthesis, we compared early $\mathrm{JCT}_{\mathrm{dog}}$ and $\mathrm{TRD}_{\text {dog }}$ sites of accumulation with the bright red DsRed fluorescence that accompanies accumulation and concentration of CSQ2-DsRed in rough ER [18, 28].

After only $24 \mathrm{~h}$ of co-expression with CSQ2-DsRed, both $\mathrm{TRD}_{\mathrm{dog}}$ and $\mathrm{JCT}_{\mathrm{dog}}$ showed their relatively typical perinuclear patterns of jSR filling (Fig. 5A). However, by $48 \mathrm{~h}, \mathrm{JCT}_{\mathrm{dog}}$ and $\mathrm{TRD}_{\mathrm{dog}}$ had accumulated to very high relative levels in and around the nuclear envelope (Fig. 5A), co-localized with CSQ2-DsRed in juxtanuclear rough ER (Fig. 5B). The bright red fluorescence that occurs with formation of DsRed tetramers [29], was previously shown to correspond to the ectopic polymerization of CSQ2-DsRed in cardiac rough ER that prevents its normal anterograde trafficking [18].

To show that newly made $\mathrm{TRD}_{\mathrm{dog}}$ was binding to CSQ2 through its well-characterized interaction domain [15], we compared the effect of CSQ2-DsRed on trafficking of newly 
accumulated ${ }^{\text {del }}$ TRD, a deletion mutant of TRD $_{\text {dog }}$ absent the canonical CSQ2-binding site

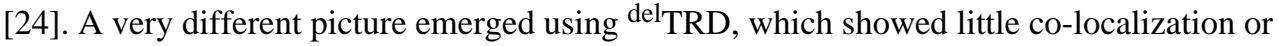
restricted anterograde movement with CSQ2-DsRed (Fig. 5). These data suggested that CSQ2-DsRed, TRD, and JCT were synthesized at a common intracellular site of rough ER, likely in and near the nuclear envelope. These data also demonstrated that TRD stably bound to CSQ2 in situ. Based upon the known similarities in CSQ2-binding properties for JCT and TRD [16, 30, 31], and homologous CSQ2-binding sequences present in JCT [15], these data suggest that JCT was also binding specifically to CSQ2 in situ.

\subsection{Morphological distinctions between smooth ER and jSR}

We previously concluded that expression of CSQ2-DsRed produces a form of the protein that cannot properly traffic to endogenous jSR sites due to its ectopic polymerization near sites of biosynthesis [18]. This is consistent with the idea that retention of different forms of the CSQ protein CSQ (e.g. CSQ1, CSQ2, and CSQ2-DsRed) is uniquely determined by their polymerization, which is sensitive to levels of $\mathrm{Ca}^{2+}$ and ionic milieu [18, 20].

In the current study, we extended these previous observations to find that lower levels of CSQ2-DsRed fluorescence populated the secretory pathway beyond the nuclear envelope and juxtaposed cisternae, into ER tubules between the two myonuclei and extending well into the periphery of the cell (Fig. 6A). This CSQ2-DsRed-positive ER very often appeared as circular or polygonal tubules, presumably depending upon its orientation in optical slices. The underlying MT network in these regions suggested that these more extensive smooth ER components might lie along the dense, longitudinally directed MT network (Fig. 6B). Along a central axis between nuclei connecting the nuclei, CSQ2-DsRed further appeared as intertwined tubular and polygonal membranes (Fig. 6C,D). To compare the early pathway of $\mathrm{TRD}_{\text {dog }}$ trafficking with the early ER subcompartments of CSQ2-DsRed, we cooverexpressed TRD $\mathrm{dog}_{\mathrm{dog}}$ and CSQ2-DsRed. Comparisons of DsRed red fluorescence with green anti-TRD $D_{\text {dog }}$ immunofluorescence showed that newly made $T R D_{\text {dog }}$ co-localized with CSQ2-DsRed around nuclei and even along the longitudinal ER tubules (Fig. 7A-C). The concentration in and around the nuclear envelopes was very marked, and contrasted with the pattern of early accumulation observed when $\mathrm{TRD}_{\mathrm{dog}}$ or $\mathrm{JCT}_{\mathrm{dog}}$ were expressed alone (cf. Fig. 2-4).

In addition to the majority of $\mathrm{TRD}_{\mathrm{dog}}$ that co-localized with CSQ2-DsRed, there was also a population of $\mathrm{TRD}_{\mathrm{dog}}$ molecules that concentrated in peripheral jSR puncta (Fig. 7C). These molecules were likely those synthesized prior to CSQ2-DsRed polymerization (at 24-30 h [18]). The resultant ER and jSR "double labeling” highlighted interesting differences in ER and jSR. After about $36 \mathrm{~h}$, the smooth ER began filling with CSQ2-DsRed, and though it overlapped with jSR (Fig. 7D,E), it generated a non-punctate pool of ER, suggesting that smooth ER intersected with or overlapped jSR sites but was not obligated to concentrate protein there.

Another interesting feature of early jSR protein biosynthesis was an apparent segregation of newly biosynthesized jSR proteins within the rough ER itself Fig. 7D,E). Thus, within the nuclear envelope, bright fluorescent areas (large puncta) were typically seen that aligned with more distal markers of jSR puncta (Fig. 7E). This early sorting into sarcomeric patterns 
suggested that ribosomes might adhere non-homogenously to rough ER subdomains as part of some wider structural biosynthetic structures.

To further investigate the interface between the longitudinal smooth ER (of CSQ2-DsRed) and early jSR puncta of newly synthesized TRD dog $_{\text {, we used }}{ }^{\text {del }}$ TRD to circumvent its in

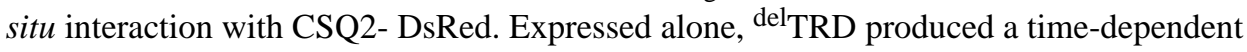
change in fluorescent puncta that was similar to that of wild type $\mathrm{TRD}_{\mathrm{dog}}$ and $\mathrm{JCT}_{\text {dog }}$ proteins (data not shown). When co-expressed with CSQ2-DsRed for $48 \mathrm{~h},{ }^{\text {del TRD }}$ immunofluorescence labeled ER/SR subcompartments that were morphologically distinct from the CSQ2-DsRed-labeled ER subcompartment (Fig. 8). CSQ2-DsRed was localized to the nuclear envelope and smooth longitudinal ER, while del TRD immunofluorescence was relatively low in CSQ2-DsRed-containing smooth ER, concentrating instead in puncta outside the boundaries of the most intense areas of red fluorescence. At incubation times of 24-36 h, one could more readily observe transitions from red-to-green ER tubules close to the nuclear surfaces (Fig. 8D), longer incubation times of 36-48 $\mathrm{h}$ led to an increased CSQ2DsRed accumulation, increased DsRed fluorescence, and an apparent swelling of the smooth ER (Fig. 8A,E). Interestingly, even under the circumstances of ER proliferation, jSR sites marked by ${ }^{\text {del }}$ TRD immunofluorescence still maintained a distinct separation from DsRed fluorescence (Fig. 8A,E).

Clear areas of transition could be discerned where longitudinally oriented CSQ2-DsRedpositive ER gave way to transversely aligned puncta ${ }^{\text {del }}$ TRD-containing immunofluorescence (white arrows, Fig. 8, panels B2, C2). These areas of apparent ER-toSR transition occurred over a radial distance of only a few hundred nanometers. On the

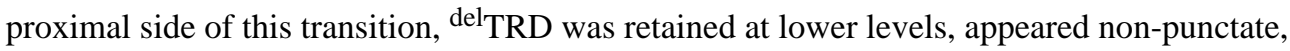
and co-localized with CSQ2-DsRed. On the distal side of the transition, delTRD was more punctate and co-localized with jSR. Thus, smooth plus rough ER compartments (CSQ2DsRed-postive) are distinguished both by the fact that CSQ2-DsRed appears unable to exit, and that TRD (delTRD) fails to accumulate. JSR, on the other hand, is obviously marked by the beginning of the formation of concentrated puncta from smooth ER protein traffic. It is interesting to note that punctate localization of delTRD presumably did not require binding to CSQ2 for concentrating in jSR.

\subsection{Inhibition of anterograde trafficking of JCT and TRD by nocodazole}

If trafficking of $\mathrm{JCT}_{\mathrm{dog}}$ and $\mathrm{TRD}_{\mathrm{dog}}$ away from the nuclear envelope and smooth ER towards jSR along longitudinal and transverse pathways occurred, we would predict that a MT platform exists from which molecular motors could carry the jSR cargo. To determine the effects of MT disruption on early accumulation and initial trafficking steps of JCT and TRD, we used nocodazole [32]. To ascertain possible effects of MT disruption on $\mathrm{JCT}_{\mathrm{dog}}$ and $\mathrm{TRD}_{\mathrm{dog}}$ trafficking, we allowed newly synthesized $\mathrm{JCT}_{\mathrm{dog}}$ and $\mathrm{TRD}_{\mathrm{dog}}$ to accumulate for $36 \mathrm{~h}$ in the presence of drug. Nocodazole treatment resulted in bright fluorescent rings of juxtanuclear ER, representing $\mathrm{JCT}_{\mathrm{dog}}$ and $\mathrm{TRD}_{\mathrm{dog}}$ that were prevented from trafficking away from their sites of synthesis (Fig. 9A,B). These data show an involvement of MT at the earliest sites of exit from the rough ER, and corroborate the view that juxtanuclear ER is the common site of jSR biosynthesis. 
Nocodazole treatments led to diminished MT staining throughout the cells (Fig. 9C).

Differences in MT staining were apparent when comparing anti-alpha tubulin and anti-beta tubulin, as was previously reported in mouse skeletal muscle immunostaining [33], suggesting that cardiac muscle might also contain immunologically distinct pools of MTs for transverse (radial) versus longitudinal (axial) ER/SR traffic. Protein levels of JCT and TRD detected by immunoblotting remained similar in nocodazole treated and untreated cells (data not shown).

\section{Discussion}

Studies of jSR structure have outpaced our understanding of cardiomyocyte cell biology, leading to knowledge of changes in jSR structure in chronic disease with little context for understanding its mechanisms. In this study, we have characterized the changes in localization of newly made $\mathrm{JCT}_{\mathrm{dog}}$ and $\mathrm{TRD}_{\mathrm{dog}}$ over the initial $48 \mathrm{~h}$ of expression. The results of these studies serve as a basis for understanding the cellular physiology that accompanies co-translational and posttranslational features of jSR proteins. Biochemical changes that occur within early subdomains of the cardiac secretory pathway include: trimming of the CSQ2 glycan in heart to very low levels of mannose (Man1-5) [34], replacement of CSQ2 in normal heart tissue with less trimmed CSQ2 glycoproteins in failed canine tissue [35, 36], regulation by TRD glycosylation of its breakdown by the proteasome [37], and phosphorylation of CSQ2 by protein kinase CK2 which is thought to occur in rough ER [23, 38].

\subsection{Sites of JCT and TRD biosynthesis and earliest accumulation in adult cardiomyocytes}

$\mathrm{JCT}_{\operatorname{dog}}$ and $\mathrm{TRD}_{\mathrm{dog}}$ were initially detected as fluorescent puncta near the edge of nuclei, indicating a close proximity to rough ER. Junctional SR sites in close proximity to nuclei have been previously described [39]. When $\mathrm{TRD}_{\mathrm{dog}}$ was co-expressed with CSQ2-DsRed, the majority of $\mathrm{TRD}_{\mathrm{dog}}$ did not form jSR puncta but instead localized to juxtanuclear ER, consistent with an ER to jSR transition that no longer occurred for $\mathrm{TRD}_{\mathrm{dog}}$. The $\mathrm{TRD}_{\mathrm{dog}}$ that was not bound to CSQ2-DsRed trafficked normally to jSR (Fig. 7), and likely represented $\mathrm{TRD}_{\mathrm{dog}}$ that was translated prior to accumulation of the high levels of CSQ2DsRed needed to polymerize and exhibit red fluorescence [18, 29].

Fusion of the fluorophore DsRed with CSQ2 produces a unique protein marker of cardiac rough ER that, once formed, restricts its anterograde trafficking [18]. Rough ER-localized CSQ-DsRed was able to form a veritable net that bound to JCT $\mathrm{dog}_{\text {and }}$ and $\mathrm{T}_{\mathrm{dog}}$, preventing their anterograde trafficking and retaining them within juxtanuclear cisternae that did not form puncta. Binding to CSQ2-DsRed was reversed when the CSQ2 binding site in TRD was deleted. The sequence-specific binding to CSQ2-DsRed in situ indicate that changes in $\mathrm{TRD}_{\mathrm{dog}}$ accumulation reflected differences in protein trafficking and not differences due to mRNA transport mRNA [40] or differential use of ribosomes among a multiple rough ER sites identified in electron microscope studies [41]. Thus, the data suggests that the accumulation of $\mathrm{JCT}_{\operatorname{dog}}$ and $\mathrm{TRD}_{\mathrm{dog}}$ in juxtanuclear jSR puncta after as soon as $12 \mathrm{~h}$ after virus treatment represents actual protein traffic and not the appearance of new sites of

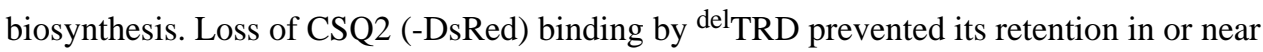


the nuclear envelope, but did not prevent its formation of jSR puncta, demonstrating that the KEKE-motif in TRD (and presumably JCT) [15] is not necessary for its concentration in jSR.

\subsection{JSR protein trafficking away from the nuclear envelope}

The classic depiction of jSR is that of a longitudinal array of ER/SR tubules that terminate as SR/SL junctions near Z-lines. This depiction has not been scrutinized in terms of its relevance to protein trafficking towards and away from these SR junctions, reportedly an ongoing dynamic process [21]. $\mathrm{JCT}_{\mathrm{dog}}$ and $\mathrm{TRD}_{\mathrm{dog}}$ molecules accumulated at everincreasing distances from the nucleus, mapping out an apparent transverse trafficking aligned near Z-lines of corresponding sarcomeres. The strongest indication of a transverseoriented trafficking was the fluorescent tracks of newly-made $\mathrm{JCT}_{\mathrm{dog}}$ and $\mathrm{TRD}_{\mathrm{dog}}$ that radiated away from individual nuclei over the first $24 \mathrm{~h}$ of expression (Figs. 3,4). Transport from rough ER to jSR along such radial tracks from areas around individual nuclei provided for immediate jSR filling by newly synthesized proteins.

Using scanning electron microscopy, Ogata and Yamasaki [42] described a prominent set of ER tubules in the adult rat cardiomyocyte that are appropriately oriented to function as the anterograde protein trafficking pathway observed in this study. These Z-tubules (50-80 nm diameter) run parallel to sarcolemmal T-tubules $(70-100 \mathrm{~nm})$. Abundant tiny projections visible by SEM were interpreted as jSR protein complexes, consistent with a transverse network of tubules that intermittently interact with T-tubules to form jSR sites. Cardiac ER tubules capable of the transverse/radial trafficking are also evident in data from other laboratories [43-45]. Cardiac jSR cisternae receive input from multiple anastomosing ER tubules [46-48], so the radial protein traffic seen in our studies need not correspond to a single ER tubule.

In addition to transverse trafficking of $\mathrm{JCT}_{\mathrm{dog}}$ and $\mathrm{TRD}_{\mathrm{dog}}$, it was apparent from the data that jSR puncta could also be populated by ER aligned along the axial length of the myocyte. Nowhere was this more prominent than in areas between the two nuclei (cf. Figs. 6,7). Strands of polygonal ER, visualized by CSQ2-DsRed fluorescence, served as sites from which transverse jSR could be generated between the nuclei. This longitudinal ER was strongly labeled by CSQ2-DsRed (cf. Fig. 6A) but was also populated by newly made $\mathrm{TRD}_{\text {dog }}$ and $\mathrm{JCT}_{\text {dog }}$, resulting in binding to and co-localization with CSQ2-DsRed (Fig. 7). Longitudinal/axial trafficking of jSR proteins was also apparent at early time points of $\mathrm{TRD}_{\text {dog }}$ and $\mathrm{JCT}_{\text {dog }}$ expression, beginning only after transverse/radial trafficking away from juxtanuclear sites had occurred. Visible accumulations in ER along longitudinal microtubules were only occasionally seen (e.g., see Fig. 8D). The actual transitions of longitudinal to transverse trafficking were likely to be very rapid once proteins reached intracellular sites of ER to jSR transition. Prior to the development of longitudinal trafficking, jSR protein accumulations were restricted to two isolated juxtanuclear sites (cf. $24 \mathrm{~h}$ time points, Figs. 2,3).

Significant ultrastructural evidence exists for axial connections of jSR sites, although the origin of the axial tubules is not certain [39, 49]. Vega et al. [21] examined motile corbular SR boutons in the SR of adult ventricular myocytes labeled by adenoviral expression of red 
fluorescent protein fused to the well-known ER-retrieval tetrapeptide (RFP-KDEL). Their data show that RFP-KDEL fluorescence labels the nuclear envelope to high levels, and along transverse membrane ribbons. Live cell imaging of motile (corbular) SR boutons in the cell periphery that contain ryanodine receptor showed longitudinal movements across Zline boundaries over the course of several minutes in neonatal cells, whereas adult cardiomyocytes exhibited measurable fluctuations about the Z-line, evidence of continual longitudinal trafficking once jSR proteins have populated sites in the cell periphery.

\subsection{Cardiac smooth ER and transitions to jSR}

Beyond the more-centrally localized internuclear strands of ER, a wide expanse of concentric layers of CSQ2-DsRed-containing ER could be seen stretching longitudinally across the entire cell (cf. Figs. 6-8). CSQ2-DsRed is an imperfect marker for smooth ER because it generates brighter fluorescence closer to sites of biosynthesis that diminishes with distance. Visualized in optical planes through the center of nuclei, CQ2-DsRed-positive cardiac ER often appeared as longitudinal bands connected by polygonal tubules (cf. Fig. 6A). It seems reasonable to assume that this primarily axial component of cardiac ER corresponds to tubules that have been historically characterized as "longitudinal" or "free" SR in the electron microscope $[1,2,50]$, but again, fluorescence intensity favors the more proximal lumens where CSQ2-DsRed levels first elevate.

A second subcompartment of the smooth ER could also be distinguished. A distinct convoluted set of innermost tubules lay between the nuclei and as pyramidal peaks at the outer ends of the cell. This central smooth ER was not sarcomeric in distribution and did not appear to result in SR puncta of CSQ2-DsRed (cf. Fig. 6D). This central core of ER accumulated relatively high concentrations of CSQ2-DsRed, but only low levels of the $\mathrm{JCT}_{\mathrm{dog}}$ and $\mathrm{TRD}_{\mathrm{dog}}$. The localized nature of this subcompartment suggested that these membranes could play a role in other ER-based processes and less directed at ER protein traffic and jSR filling. We were not able to demonstrate that this region was enriched in more distal components of the secretory pathway (e.g., ERGIC or Golgi) using antibodies to presumed marker proteins (N. Sleiman and S. Cala, personal observations). Our findings here are in overall agreement with a diverse set of findings from past studies of adult skeletal muscle myocyte ER/SR biology [32, 51, 52], most of which were carried out using microscopy of native (steady-state) markers.

In nonmuscle cells, sorting and trafficking of newly synthesized resident ER proteins requires specializations of the ER such as transitional ER, ERGIC, and Golgi. ER exit requires the binding of a protein complex to the ER that packages cargo proteins in COPII transport vesicles (see [53] for review). COPII coat proteins such as sec23 are commonly used as markers of ER exit sites. In cultured cardiomyocytes, the COPII marker sec 23 was previously shown to be present along Z-lines although seemingly not co-localized to jSR puncta [18], in agreement with findings in skeletal muscle myocytes [51]. Studies by Kaisto and Metsikko [51] suggested that trafficking in cultured skeletal myofibrils of the vesicular stomatitis virus G-protein was sorted into distinct ER/SR pathways depending upon its secretory status. Studies of other protein pathways (e.g. longitudinal SR, secretion) are needed to elucidate more distal pathways in the cardiomyocyte. 
Our data distinguished between ER subcompartments that concentrate CSQ2-DsRed and ER subcompartments that do not, but instead concentrate $\mathrm{JCT}_{\mathrm{dog}}$ and $\mathrm{TRD}_{\operatorname{dog}}$. This, we hypothesize, marks a biological distinction between ER and SR (Fig. 10). In the absence of CSQ2-DsRed, ER-to-jSR transitions were visualized in areas close to the nuclear surface, and across MT-based longitudinal smooth ER between the two nuclei. Following expression of CSQ2-DsRed, a striking shift occurred in these transitional areas towards greater distances from the nucleus. CSQ2-DsRed-containing ER appeared to expand, while jSR puncta were no longer present close to nuclei (Fig. 8,10). This shift in the ER-to-SR transition was consistently observed by $48 \mathrm{~h}$ of CSQ2-DsRed expression. It is interesting to speculate that changes in ER-jSR transition are driven by the same changes in intraluminal $\mathrm{Ca}^{2+}$ that were shown to generate spontaneous ryanodine receptor-dependent $\mathrm{Ca}^{2+}$ release in cultured cardiomyocytes [28].

CSQ2 obtained from control and failed heart tissues suggest that considerable change occurs in ER versus SR trafficking with heart failure [35, 36]. A sizable pool of a putative nonmuscle ER form (Man9,8) of CSQ2 accumulates to roughly a third of total CSQ2, and CSQ2 appears to undergo more rapid turnover in failed canine heart (more mRNA but lower overall protein levels) [36]. The facility with which CSQ2-DsRed was able to transform ERSR transitions in the current study introduces a possible mechanism by which CSQ2 changes in cardiomyopathy might occur.

\subsection{MT based ER and SR traffic}

Upon $36 \mathrm{~h}$ of treatment with the MT disrupting agent nocodazole, newly synthesized $\mathrm{TRD}_{\operatorname{dog}}$ and $\mathrm{JCT}_{\mathrm{dog}}$ failed to traffic beyond the rough ER. Perinuclear tubules containing $\mathrm{JCT}_{\mathrm{dog}}$ and $\mathrm{TRD}_{\mathrm{dog}}$ seen following nocodazole treatment might correspond to partial filling of an early ER subcompartment. Effects of nocodazole on translocon complex localization might also have occurred [54]. Sorting of translocons (e.g. Fig. 7E) might reflect an alignment of translocons with sarcomeric lengths in the untreated cells.

The co-localization of newly-made $\mathrm{JCT}_{\mathrm{dog}}$ and $\mathrm{TRD}_{\mathrm{dog}}$ (Fig. 4) suggest that jSR proteins may traffic as common cargo within large ER vesicles and tubules that interact with both dynein and kinesin [55]. ER membrane trafficking and organization is linked to MT organization through organelle-associated scaffolding proteins that interact with motor proteins of the dynein and kinesin families [56-58]. Both kinesin and dynein can exist in a given segment of trafficking ER [59], and there is evidence for both motors at work along MTs between corbular and jSR in adult cardiomyocytes [21]. With both dynein and kinesin motors present in cardiac ER, the direction of ER trafficking could be regulated by regulation of the motor proteins themselves or by associated scaffolding complexes [56]. For example, radial $\mathrm{JCT}_{\mathrm{dog}}$ and $\mathrm{TRD}_{\mathrm{dog}}$ traffic may be regulated differently from axial ER traffic. MT organizing centers (MTOC) in cardiomyocyte exist in both the nuclear envelope [60], and in multiple static Golgi complexes that extend dynamically across the cell in either direction [32].

Zhang et al. [61] showed that an increased density of MTs was responsible for redistribution of junctophilin-2 (JP2), another transmembrane jSR protein, in pressure overload-induced remodeling of heart. They reported that JP2 protein levels were not diminished but the 
protein was mis-trafficked to ER sites in or near the plasma membrane. More recently these authors showed that JP2 overexpression in transgenic mice does not affect basal $\mathrm{Ca}^{2+}$ homeostasis but protects from pathological changes due to pressure overload [62]. These findings may suggest a role for JP2 that depends more on successful flux across ER and SR compartments than on its steady-state levels.

In summary, we propose a new model of junctional SR formation that involves transverse trafficking along an ER subcompartment that is distinct from that of the abundant smooth ER, and likely becomes the so-called longitudinal SR. An important caveat of these studies is a reliance on overexpression at levels sufficient to permit early detection of jSR protein markers. While this model may provide new insights into myocardial disease processes, further research will be needed to establish these pathways and mechanisms.

\section{Acknowledgements}

We thank Cristine Smoczer, M.D., Ph.D. for critical reading of the manuscript. This work was supported by NIH R01 HL062586 (SC), and by an Incubator Grant from the Office of Vice President for Research, Wayne State University (SC).

\section{Abbreviations}

$\begin{array}{ll}\text { JCT }_{\text {dog }} & \text { canine junctin } \\ \text { TRD }_{\text {dog }} & \text { canine cardiac triadin } \\ \text { CSQ2 } & \text { calsequestrin-2 } \\ \text { jSR } & \text { junctional sarcoplasmic reticulum } \\ \text { ER } & \text { endoplasmic reticulum } \\ \text { MTs } & \text { microtubules } \\ \text { Ad.CSQ2-DsRed } & \text { calsequestrin-DsRed adenoviral vector } \\ \text { Ad.CSQ2 } & \text { calsequestrin adenoviral vector } \\ \text { T-tubules } & \text { transverse tubules } \\ \text { RyR2 } & \text { ryanodine receptor-2 } \\ \text { SERCA } & \text { SR/ER Ca }{ }^{2+} \text {-ATPase } \\ \text { JP2 } & \text { junctophilin-2 }\end{array}$

\section{References}

1. Sommer, JR.; Jennings, RB. Ultrastructure of cardiac muscle.. In: Fozzard, HA., editor. The heart and cardiovascular system. Raven Press; New York: 1986. p. 61-100.

2. Franzini-Armstrong C. Structure of sarcoplasmic reticulum. Fed Proc. 1980; 39:2403-9. [PubMed: 7371874]

3. Fleischer S, Inui M. Biochemistry and biophysics of excitation-contraction coupling. Annu Rev Biophys Biophys Chem. 1989; 18:333-64. [PubMed: 2660829]

4. Bers DM, Shannon TR. Calcium movements inside the sarcoplasmic reticulum of cardiac myocytes. J Mol Cell Cardiol. 2013; 58:59-66. [PubMed: 23321551] 
5. Cala SE, Scott BT, Jones LR. Intralumenal sarcoplasmic reticulum $\mathrm{Ca}(2+)$-binding proteins. Semin Cell Biol. 1990; 1:265-75. [PubMed: 2103513]

6. Franzini-Armstrong C. The sarcoplasmic reticulum and the control of muscle contraction. FASEB J. 1999; 13(Suppl 2):S266-70. [PubMed: 10619141]

7. Jorgensen AO, Shen AC, Campbell KP. Ultrastructural localization of calsequestrin in adult rat atrial and ventricular muscle cells. J Cell Biol. 1985; 101:257-68. [PubMed: 4008530]

8. ones LR, Cala SE. Biochemical evidence for functional heterogeneity of cardiac sarcoplasmic reticulum vesicles. J Biol Chem. 1981; 256:11809-18. [PubMed: 6271762]

9. Diaz ME, Graham HK, O'Neill S C, Trafford AW, Eisner DA. The control of sarcoplasmic reticulum Ca content in cardiac muscle. Cell Calcium. 2005; 38:391-6. [PubMed: 16139353]

10. Franzini-Armstrong C, Jorgensen AO. Structure and development of E-C coupling units in skeletal muscle. Annu Rev Physiol. 1994; 56:509-34. [PubMed: 8010750]

11. Meissner G. Ryanodine receptor/Ca2+ release channels and their regulation by endogenous effectors. Annu Rev Physiol. 1994; 56:485-508. [PubMed: 7516645]

12. Campbell KP, MacLennan DH, Jorgensen AO, Mintzer MC. Purification and characterization of calsequestrin from canine cardiac sarcoplasmic reticulum and identification of the 53,000 dalton glycoprotein. J Biol Chem. 1983; 258:1197-204. [PubMed: 6337133]

13. Guo W, Jorgensen AO, Jones LR, Campbell KP. Biochemical characterization and molecular cloning of cardiac triadin. J Biol Chem. 1996; 271:458-65. [PubMed: 8550602]

14. Kobayashi YM, Jones LR. Identification of triadin 1 as the predominant triadin isoform expressed in mammalian myocardium. J Biol Chem. 1999; 274:28660-8. [PubMed: 10497235]

15. Kobayashi YM, Alseikhan BA, Jones LR. Localization and characterization of the calsequestrinbinding domain of triadin 1. Evidence for a charged beta-strand in mediating the protein-protein interaction. J Biol Chem. 2000; 275:17639-46. [PubMed: 10748065]

16. Jones LR, Zhang L, Sanborn K, Jorgensen AO, Kelley J. Purification, primary structure, and immunological characterization of the $26-\mathrm{kDa}$ calsequestrin binding protein (junctin) from cardiac junctional sarcoplasmic reticulum. J Biol Chem. 1995; 270:30787-96. [PubMed: 8530521]

17. Jorgensen AO, Shen AC, Daly P, MacLennan DH. Localization of Ca2++ Mg2+-ATPase of the sarcoplasmic reticulum in adult rat papillary muscle. J Cell Biol. 1982; 93:883-92. [PubMed: 6749864]

18. McFarland TP, Milstein ML, Cala SE. Rough endoplasmic reticulum to junctional sarcoplasmic reticulum trafficking of calsequestrin in adult cardiomyocytes. J Mol Cell Cardiol. 2010 MS ID\#: JOCES/2009/061572:556-64.

19. Houle TD, Ram ML, McMurray WJ, Cala SE. Different endoplasmic reticulum trafficking and processing pathways for calsequestrin (CSQ) and epitope-tagged CSQ. Exp Cell Res. 2006; 312:4150-61. Epub 2006 Sep 20. [PubMed: 17045261]

20. Milstein ML, Houle TD, Cala SE. Calsequestrin isoforms localize to different ER subcompartments: evidence for polymer and heteropolymer-dependent localization. Exp Cell Res. 2009; 315:523-34. [PubMed: 19059396]

21. Vega AL, Yuan C, Votaw VS, Santana LF. Dynamic changes in sarcoplasmic reticulum structure in ventricular myocytes. J Biomed Biotechnol. 2011; 2011:382586. [PubMed: 22131804]

22. Kabaeva Z, Zhao M, Michele DE. Blebbistatin extends culture life of adult mouse cardiac myocytes and allows efficient and stable transgene expression. Am J Physiol Heart Circ Physiol. 2008; 294:H1667-74. [PubMed: 18296569]

23. Ram ML, Kiarash A, Marsh JD, Cala SE. Phosphorylation and dephosphorylation of calsequestrin on CK2-sensitive sites in heart. Mol Cell Biochem. 2004; 266:209-17. [PubMed: 15646044]

24. Terentyev D, Cala SE, Houle TD, Viatchenko-Karpinski S, Gyorke I, Terentyeva R, et al. Triadin overexpression stimulates excitation-contraction coupling and increases predisposition to cellular arrhythmia in cardiac myocytes. Circ Res. 2005; 96:651-8. Epub 2005 Feb 24. [PubMed: 15731460]

25. He TC, Zhou S, da Costa LT, Yu J, Kinzler KW, Vogelstein B. A simplified system for generating recombinant adenoviruses. Proc Natl Acad Sci U S A. 1998; 95:2509-14. [PubMed: 9482916] 
26. Zhang L, Kelley J, Schmeisser G, Kobayashi YM, Jones LR. Complex formation between junctin, triadin, calsequestrin, and the ryanodine receptor. Proteins of the cardiac junctional sarcoplasmic reticulum membrane. J Biol Chem. 1997; 272:23389-97. [PubMed: 9287354]

27. Laemmli UK. Cleavage of structural proteins during the assembly of the head of bacteriophage T4. Nature. 1970; 227:680-5. [PubMed: 5432063]

28. Guo A, Cala SE, Song LS. Calsequestrin accumulation in rough endoplasmic reticulum promotes perinuclear Ca2+ release. J Biol Chem. 2012; 287:16670-80. [PubMed: 22457350]

29. Campbell RE, Tour O, Palmer AE, Steinbach PA, Baird GS, Zacharias DA, et al. A monomeric red fluorescent protein. Proc Natl Acad Sci U S A. 2002; 99:7877-82. [PubMed: 12060735]

30. Mitchell RD, Simmerman HK, Jones LR. Ca2+ binding effects on protein conformation and protein interactions of canine cardiac calsequestrin. J Biol Chem. 1988; 263:1376-81. [PubMed: 3335548]

31. Houle TD, Ram ML, Cala SE. Calsequestrin mutant D307H exhibits depressed binding to its protein targets and a depressed response to calcium. Cardiovasc Res. 2004; 64:227-33. [PubMed: 15485681]

32. Oddoux S, Zaal KJ, Tate V, Kenea A, Nandkeolyar SA, Reid E, et al. Microtubules that form the stationary lattice of muscle fibers are dynamic and nucleated at Golgi elements. J Cell Biol. 2013; 203:205-13. [PubMed: 24145165]

33. Prins KW, Humston JL, Mehta A, Tate V, Ralston E, Ervasti JM. Dystrophin is a microtubuleassociated protein. J Cell Biol. 2009; 186:363-9. [PubMed: 19651889]

34. O'Brian JJ, Ram ML, Kiarash A, Cala SE. Mass spectrometry of cardiac calsequestrin characterizes microheterogeneity unique to heart and indicative of complex intracellular transit. J Biol Chem. 2002; 277:37154-60. [PubMed: 12147690]

35. Kiarash A, Kelly C, Phinney B, Valdivia H, Abrams J, Cala S. Defective glycosylation of calsequestrin in heart failure. Cardiovasc Res. 2004; 63:264-72. [PubMed: 15249184]

36. Jacob S, Sleiman NH, Kern S, Jones LR, Sala-Mercado JA, McFarland TP, et al. Altered calsequestrin glycan processing is common to diverse models of canine heart failure. Mol Cell Biochem. 2013; 377:11-21. [PubMed: 23456435]

37. Milstein ML, McFarland TP, Marsh JD, Cala SE. Inefficient glycosylation leads to high steadystate levels of actively degrading cardiac triadin-1. J Biol Chem. 2008; 283:1929-35. [PubMed: 18025088]

38. McFarland TP, Sleiman NH, Yaeger DB, Cala SE. The cytosolic protein kinase CK2 phosphorylates cardiac calsequestrin in intact cells. Mol Cell Biochem. 2011; 353:81-91. [PubMed: 21431367]

39. Escobar M, Cardenas C, Colavita K, Petrenko NB, Franzini-Armstrong C. Structural evidence for perinuclear calcium microdomains in cardiac myocytes. J Mol Cell Cardiol. 2011; 50:451-9. [PubMed: 21147122]

40. Nissinen M, Kaisto T, Salmela P, Peltonen J, Metsikko K. Restricted distribution of mRNAs encoding a sarcoplasmic reticulum or transverse tubule protein in skeletal myofibers. J Histochem Cytochem. 2005; 53:217-27. [PubMed: 15684334]

41. Slade AM, Severs NJ. Rough endoplasmic reticulum in the adult mammalian cardiac muscle cell. J Submicrosc Cytol. 1985; 17:531-6. [PubMed: 4078944]

42. Ogata T, Yamasaki Y. High-resolution scanning electron microscopic studies on the threedimensional structure of the transverse-axial tubular system, sarcoplasmic reticulum and intercalated disc of the rat myocardium. Anat Rec. 1990; 228:277-87. [PubMed: 2260783]

43. Brochet DX, Yang D, Di Maio A, Lederer WJ, Franzini-Armstrong C, Cheng H. Ca2+ blinks: rapid nanoscopic store calcium signaling. Proc Natl Acad Sci U S A. 2005; 102:3099-104. [PubMed: 15710901]

44. Hayashi T, Martone ME, Yu Z, Thor A, Doi M, Holst MJ, et al. Three-dimensional electron microscopy reveals new details of membrane systems for Ca2+ signaling in the heart. J Cell Sci. 2009; 122:1005-13. [PubMed: 19295127]

45. Forbes MS, van Neil EE. Membrane systems of guinea pig myocardium: ultrastructure and morphometric studies. Anat Rec. 1988; 222:362-79. [PubMed: 2465704] 
46. Jayasinghe I, Crossman D, Soeller C, Cannell M. Comparison of the organization of T-tubules, sarcoplasmic reticulum and ryanodine receptors in rat and human ventricular myocardium. Clin Exp Pharmacol Physiol. 2012; 39:469-76. [PubMed: 21790719]

47. Pinali C, Bennett H, Davenport JB, Trafford AW, Kitmitto A. Three-dimensional reconstruction of cardiac sarcoplasmic reticulum reveals a continuous network linking transverse-tubules: this organization is perturbed in heart failure. Circ Res. 2013; 113:1219-30. [PubMed: 24044951]

48. Soeller C, Baddeley D. Super-resolution imaging of EC coupling protein distribution in the heart. J Mol Cell Cardiol. 2013; 58:32-40. [PubMed: 23159441]

49. Asghari P, Schulson M, Scriven DR, Martens G, Moore ED. Axial tubules of rat ventricular myocytes form multiple junctions with the sarcoplasmic reticulum. Biophys J. 2009; 96:4651-60. [PubMed: 19486687]

50. Porter KR, Palade GE. Studies on the endoplasmic reticulum. III. Its form and distribution in striated muscle cells. J Biophys Biochem Cytol. 1957; 3:269-300. [PubMed: 13438910]

51. Kaisto T, Metsikko K. Distribution of the endoplasmic reticulum and its relationship with the sarcoplasmic reticulum in skeletal myofibers. Exp Cell Res. 2003; 289:47-57. [PubMed: 12941603]

52. Volpe P, Villa A, Podini P, Martini A, Nori A, Panzeri MC, et al. The endoplasmic reticulumsarcoplasmic reticulum connection: distribution of endoplasmic reticulum markers in the sarcoplasmic reticulum of skeletal muscle fibers. Proc Natl Acad Sci U S A. 1992; 89:6142-6. [PubMed: 1631100]

53. Zanetti G, Pahuja KB, Studer S, Shim S, Schekman R. COPII and the regulation of protein sorting in mammals. Nat Cell Biol. 2012; 14:20-8. [PubMed: 22193160]

54. ikonov AV, Hauri HP, Lauring B, Kreibich G. Climp-63-mediated binding of microtubules to the ER affects the lateral mobility of translocon complexes. J Cell Sci. 2007; 120:2248-58. [PubMed: 17567679]

55. Bola B, Allan V. How and why does the endoplasmic reticulum move? Biochem Soc Trans. 2009; 37:961-5. [PubMed: 19754432]

56. Fu MM, Holzbaur EL. Integrated regulation of motor-driven organelle transport by scaffolding proteins. Trends Cell Biol. 2014

57. Allan VJ. Cytoplasmic dynein. Biochem Soc Trans. 2011; 39:1169-78. [PubMed: 21936784]

58. Hirokawa N, Noda Y, Tanaka Y, Niwa S. Kinesin superfamily motor proteins and intracellular transport. Nat Rev Mol Cell Biol. 2009; 10:682-96. [PubMed: 19773780]

59. Zadeh AD, Cheng Y, Xu H, Wong N, Wang Z, Goonasekara C, et al. Kif5b is an essential forward trafficking motor for the Kv1.5 cardiac potassium channel. J Physiol. 2009; 587:4565-74. [PubMed: 19675065]

60. Kronebusch PJ, Singer SJ. The microtubule-organizing complex and the Golgi apparatus are colocalized around the entire nuclear envelope of interphase cardiac myocytes. J Cell Sci. 1987; 88(Pt 1):25-34. [PubMed: 3327863]

61. Zhang C, Chen B, Guo A, Zhu Y, Miller JD, Gao S, et al. Microtubule-mediated defects in junctophilin-2 trafficking contribute to myocyte transverse-tubule remodeling and $\mathrm{Ca} 2+$ handling dysfunction in heart failure. Circulation. 2014; 129:1742-50. [PubMed: 24519927]

62. Guo A, Zhang X, Iyer VR, Chen B, Zhang C, Kutschke WJ, et al. Overexpression of junctophilin-2 does not enhance baseline function but attenuates heart failure development after cardiac stress. Proc Natl Acad Sci U S A. 2014; 111:12240-5. [PubMed: 25092313] 


\section{Highlights}

- Junctional SR protein synthesis occurs next to the nucleus in adult cardiomyocytes.

- ER membrane containing triadin and junctin traffics directly to jSR aligned with Z---lines/T---tubules.

- Longitudinal SR is actually smooth ER that extends from juxtanuclear rough ER, and marked by CSQ2---DsRed polymers

- Longitudinal SR/smooth ER does not generate jSR puncta

- High levels of localized CSQ2---DsRed lead to smooth ER expansion and reduced creation of jSR 


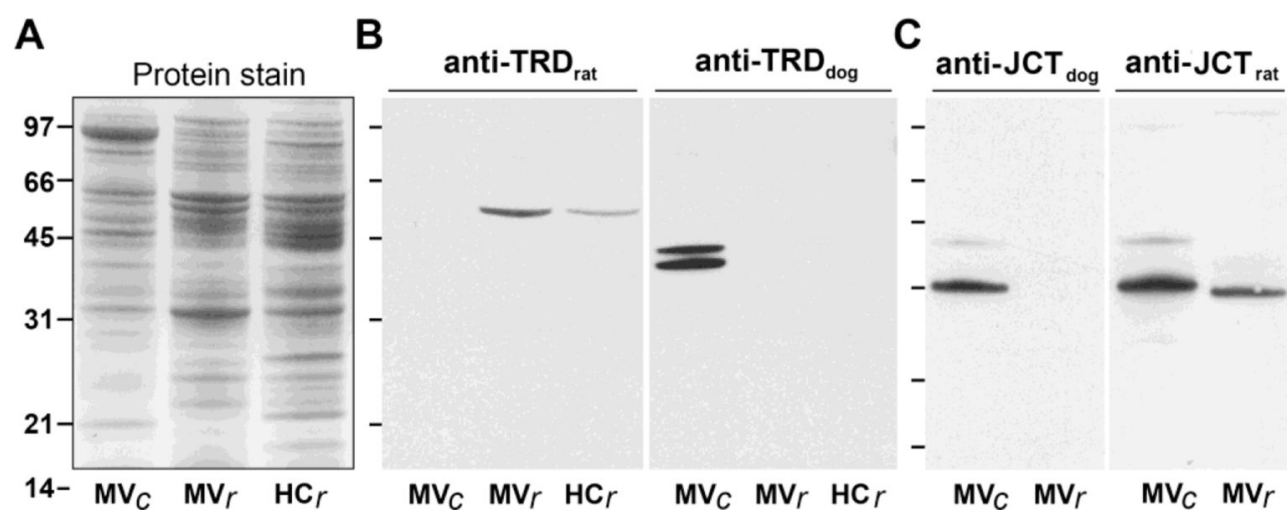

Fig. 1. Specificity of anti-TRD and anti-JCT antibodies

Samples $(50 \mu \mathrm{g})$ of canine heart microsomes (MVc), rat heart microsomes (MVr) and primary rat cardiomyocytes ( $\mathrm{HCr}$ ) were analyzed by SDS-PAGE (10\% acrylamide) and transferred to nitrocellulose. (A) Amido black stained nitrocellulose, molecular weight markers in kDa. (B) Immunoblotting with antibodies anti-TRD $\mathrm{Tat}_{\text {and }}$ anti-JCT $\mathrm{Jog}_{\mathrm{d}}$ (C) Immunoblotting with anti-JCT $\mathrm{Jog}_{\mathrm{dog}}$ and anti-JCT $\mathrm{Jat}_{\text {rat }}$ 


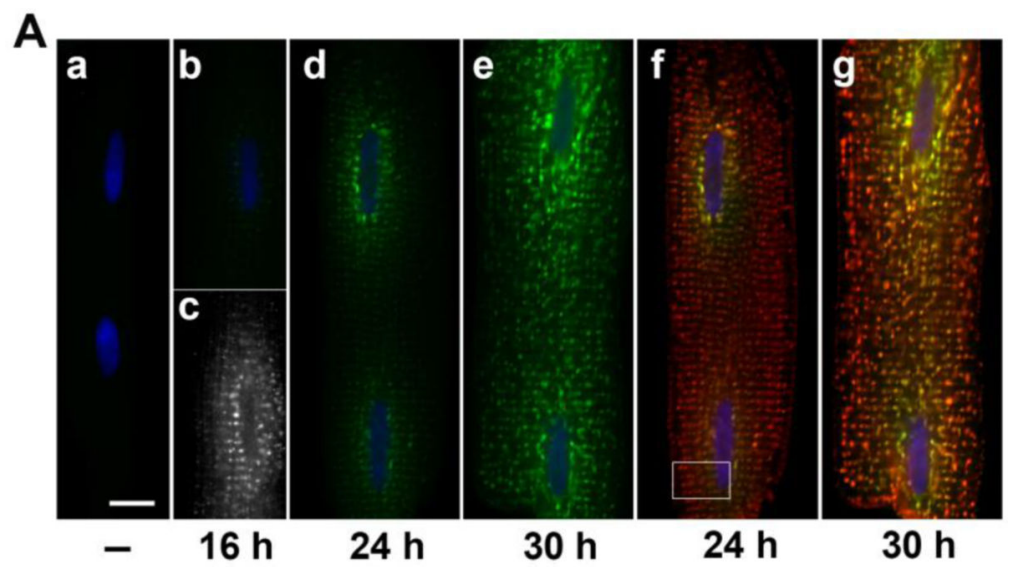

B

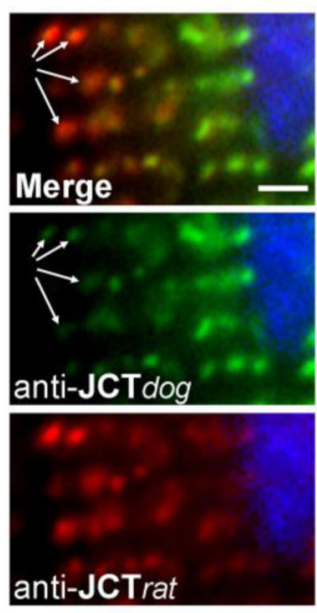

C

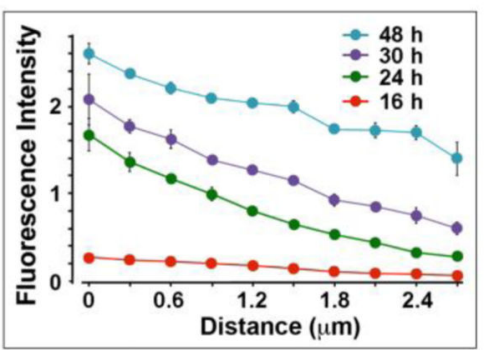

D

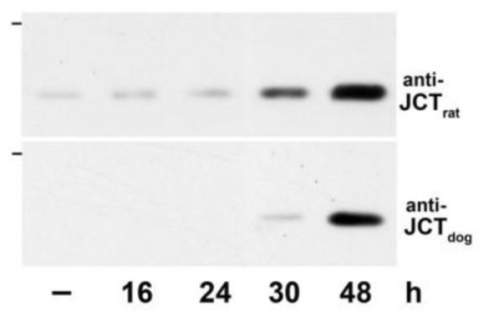

Fig 2. Initial $\mathbf{J C T}_{\mathbf{d o g}}$ accumulation at juxtanuclear sites Coverslips containing cardiomyocytes were untreated (-) or treated with JCT $\left(\mathrm{JCT}_{\mathrm{dog}}\right)$ adenovirus for 16,24 , and $30 \mathrm{~h}$, then fixed, and remaining cells harvested for immunoblotting. Cells were double-labeled with anti-JCT $\mathrm{dog}_{\text {(green) and anti-JCT }}$ (red) at each time point. Nuclei are blue. Fluorescence images for cells were acquired using identical settings and processed offline at the same time, to permit direct comparisons. (A) Representative cells are shown for time points as indicated, either for the green channel

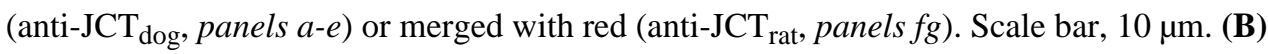
Magnification of outlined box (panel $f$ ) showing $\mathrm{JCT}_{\mathrm{dog}}$ (anti-JCT $\mathrm{T}_{\mathrm{dog}}$ immunofluorescence) appearing initially at juxtanuclear sites. In contrast, anti-JCT $\mathrm{Jat}_{\text {at }}$ appears to react more strongly with $\mathrm{JCT}_{\text {rat }}$ than $\mathrm{JCT}_{\text {dog }}$ (also see Table I), leading to a more dispersed pattern across the cell width, but with many distinct puncta showing co-localization of opposing relative immunoreactivities (arrows). Scale bar, $2 \mu \mathrm{m}$. (C) Anti-JCT dog $_{\text {immunofluorescence }}$ was quantified for confocal images in the plane of the nucleus for 15 cells at each of four incubation times. Mean levels of fluorescence $( \pm S D)$ were integrated across contiguous transverse distances of $0.3 \mu \mathrm{M}$, using a $5 \mu \mathrm{M}$ scan width sufficient to include three Z-lines (NIH ImageJ), starting with the most juxtanuclear fluorescence (puncta). Identical microscope and camera settings used for all images were adjusted to obtain suitable 
fluorescence for the $16 \mathrm{~h}$ time point, and used for all coverslips without further offline adjustments. Mean fluorescence intensities calculated at increasing distances from the nuclear edge generally represented values from less cells, as sarcomeric widths varied among cells. (D) Immunoblot analysis of the time course of $\mathrm{JCT}_{\mathrm{dog}}$ expression, visualized with anti-JCT $\mathrm{Jat}_{\text {rat }}$ (detecting both endogenous and exogenous forms) and anti-JCT $\mathrm{Jdog}_{\mathrm{d}}$ (detecting only the exogenous form of JCT). Molecular weight marker on left is $31 \mathrm{kDa}$ (10\% Laemmli gel). 


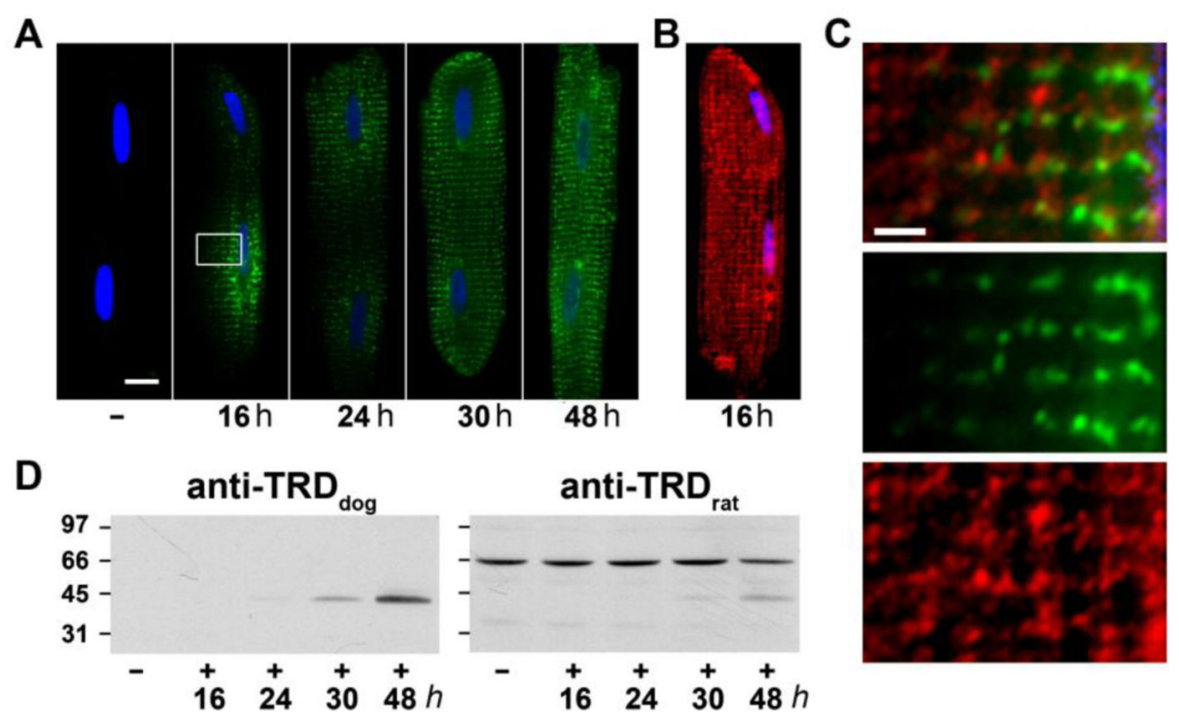

Fig. 3. TRD $_{\text {dog }}$

accumulation at juxtanuclear sites Coverslips containing cardiomyocytes were untreated $(-)$, or treated with $\mathrm{TRD}_{\mathrm{dog}}$ adenovirus for $16,24,30$, or $48 \mathrm{~h}$, then fixed, and remaining cells harvested for immunoblotting. Cells were double-labeled with anti-TRD $\mathrm{dog}_{\text {(green) and }}$ anti-TRD $\mathrm{D}_{\text {rat }}(\mathrm{red})$ at each time point. Nuclei are blue. Fluorescence images for cells were acquired using identical settings and processed offline at the same time, to permit direct comparisons. (A) Representative cells are shown for time points as indicated for anti$\mathrm{TRD}_{\mathrm{dog}}$ alone. (B) Immunofluorescence for native TRD (anti-TRD rat) for the $16 \mathrm{~h}$ time point. (C) Magnification of outlined box (panel $A, 16 \mathrm{~h}$ ) showing $\mathrm{TRD}_{\mathrm{dog}}$ appearing first at juxtanuclear sites. Scale bar $2 \mu \mathrm{m}$. (D) Immunoblot analysis of cardiomyocyte extracts showing $\mathrm{TRD}_{\mathrm{dog}}$ and $\mathrm{TRD}_{\text {rat }}$ with increasing times of $\mathrm{TRD}_{\mathrm{dog}}$ expression, as indicated. The $\mathrm{TRD}_{\mathrm{dog}}$ immunoblot was counter-stained with anti-TRD $\mathrm{Tat}_{\text {at }}$ to show differences in their respective mobilities. Molecular weight markers are shown in $\mathrm{kDa}$ on the left. 


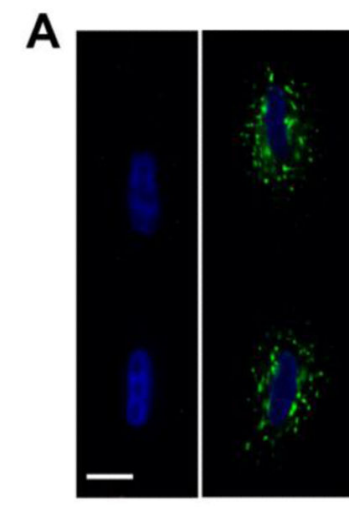

$-16 \mathrm{~h}$

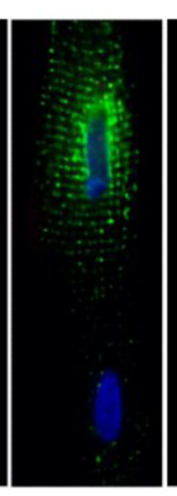

$24 \mathrm{~h}$

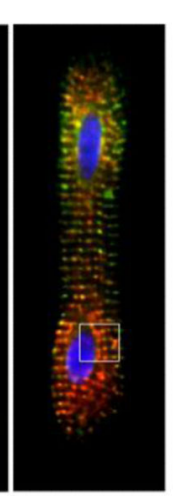

$48 \mathrm{~h}$
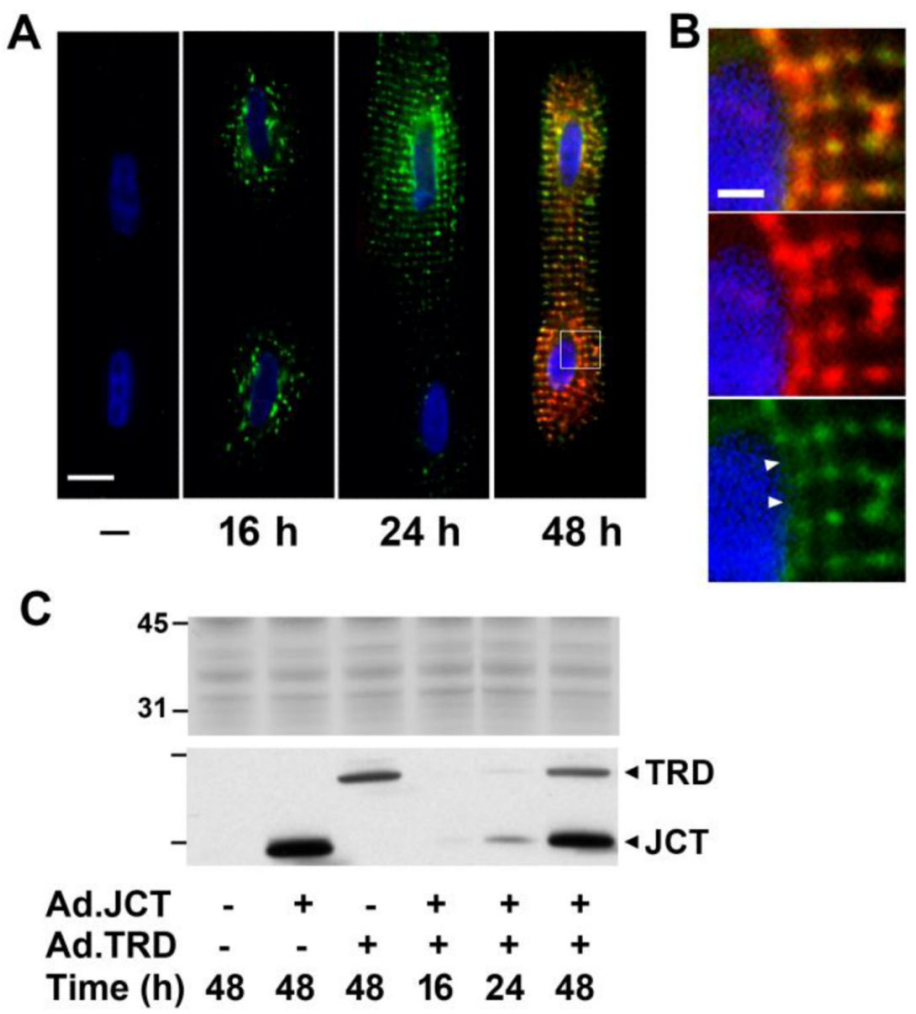

Fig 4. TRD and JCT traverse a common path to populate jSR

Cardiomyocytes were untreated (-), or co-treated with $\mathrm{TRD}_{\mathrm{dog}}$ and $\mathrm{JCT}_{\mathrm{dog}}$ adenoviruses for 16,24 , or $48 \mathrm{~h}$, then fixed for immunostaining, and remaining cells harvested for immunoblotting. (A) Immunostaining with both anti-TRD $\mathrm{Tog}_{\text {(green) and anti-JCT }}$ dog (red); nuclei are blue. Scale bar, $10 \mu \mathrm{m}$. (B) Magnification of outlined box (panel A, 48 h). Faint $\mathrm{TRD}_{\text {dog }}$ immunoreactivity can be seen in closer proximity to the nuclear surface than even the initial bright puncta (white arrowheads). Scale bar, $2 \mu \mathrm{M}$. (C) Upper Stained nitrocellulose transfer of protein extracts from untreated and treated cells at various time points as indicated. Lower Autoradiogram from immunoblot combining anti-TRD $\mathrm{dog}_{\mathrm{g}}$ and anti-JCT $\mathrm{dog}_{\mathrm{g}}$ antibodies. Molecular weight markers are indicated on the left. 


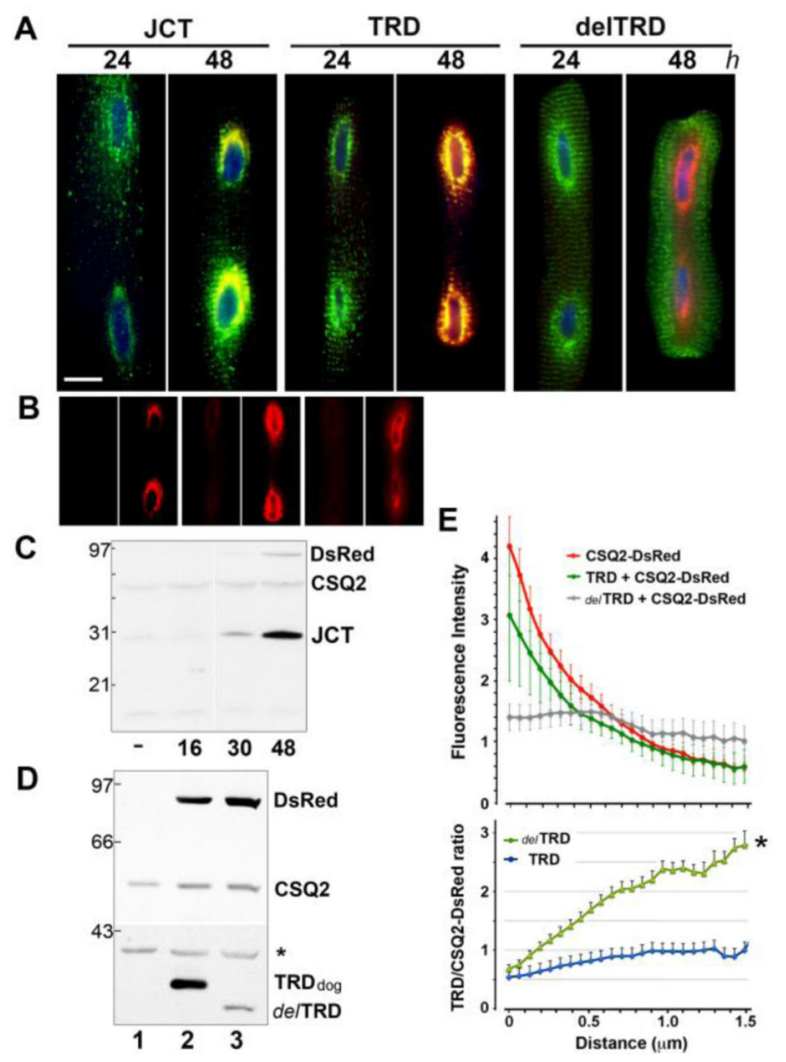

Fig 5. In situ interaction of JCT and TRD with CSQ2-DsRed in the rough ER Co-expression of CSQ2-DsRed was carried out with either $\mathrm{JCT}_{\mathrm{dog}}$ or $\mathrm{TRD}_{\mathrm{dog}}$ for the times indicated, then cells were fixed for immunostaining and remaining cells harvested for immunoblotting. (A) Cardiomyocytes co-expressing CSQ2-DsRed and either JCT, TRD $\mathrm{dog}_{\text {, }}$ or delTRD (green), for 24 or $48 \mathrm{~h}$. After $24 \mathrm{~h}$, little or no CSQ2-DsRed has polymerized, but by $48 \mathrm{~h}$, a bright red fluorescence produces a yellow or orange area representative of colocalized JCT and TRD. Meanwhile, delTRD does not form the co-localized juxtanuclear pattern. Scale bar, $10 \mu \mathrm{M}$. (B) Red channel only (of panel A) showing CSQ2-DsRed fluorescence. The panel is reduced in dimensions and trimmed to limit size. (C) Immunoblot data for time course $(\mathrm{h})$ of $\mathrm{JCT}_{\mathrm{dog}}$ and CSQ2-DsRed co-expression, using a mixture of antiCSQ2 and anti-JCT ${ }_{\text {dog }}$ antibodies. DsRed, CSQ2-DsRed; CSQ2, native rat CSQ2; lane 1 (-) shows cells before virus addition (D) Immunoblot data for cells after $48 \mathrm{~h}$ of no virus

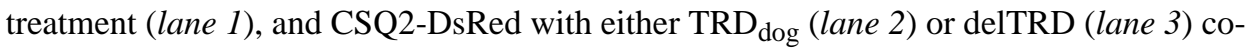

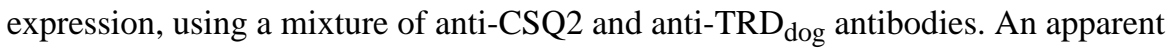
nonspecific band that appears in all lanes near $40 \mathrm{kDa}$ (asterisk, *) was not seen in other experiments. (E) (Upper panel) Anti-TRD ${ }_{\text {dog }}$ immunofluorescence and CSQ2-DsRed fluorescence were quantified for confocal images in the plane of the nucleus. Relative levels of TRD $_{\text {dog }}$ or del TRD immunofluorescence was determined as a function of distance from the nuclear edge in 15 cells each, whereas all 30 of these co-treated cells were used to determine average levels of red CSQ2-DsRed fluorescence over the same distances. Each data point represents the average levels of fluorescence within contiguous lengths of roughly $0.12 \mu \mathrm{M}$, and widths sufficient to include three Z-lines $(5 \mu \mathrm{M})$. Quantification started with the most juxtanuclear fluorescent puncta, progressing transversely, regardless of the cell 
width. Fluorescence is plotted as the fractional deviation from the average intensity for each channel $( \pm \mathrm{SE}$ ), normalized to 1.0 (values for proximal distances shown are mostly $>1.0$ ). (Lower panel) Large differences in ratios of $\mathrm{TRD}_{\mathrm{dog}}$ or del $\mathrm{TRD}$ immunofluorescence to CSQ2-DsRed fluorescence (values taken from upper panel) transversely across cell widths $(*, p=0.001$, two-way repeated measures ANOVA) reflect the highly divergent paths of the two forms of TRD in the presence of CSQ2-DsRed. 

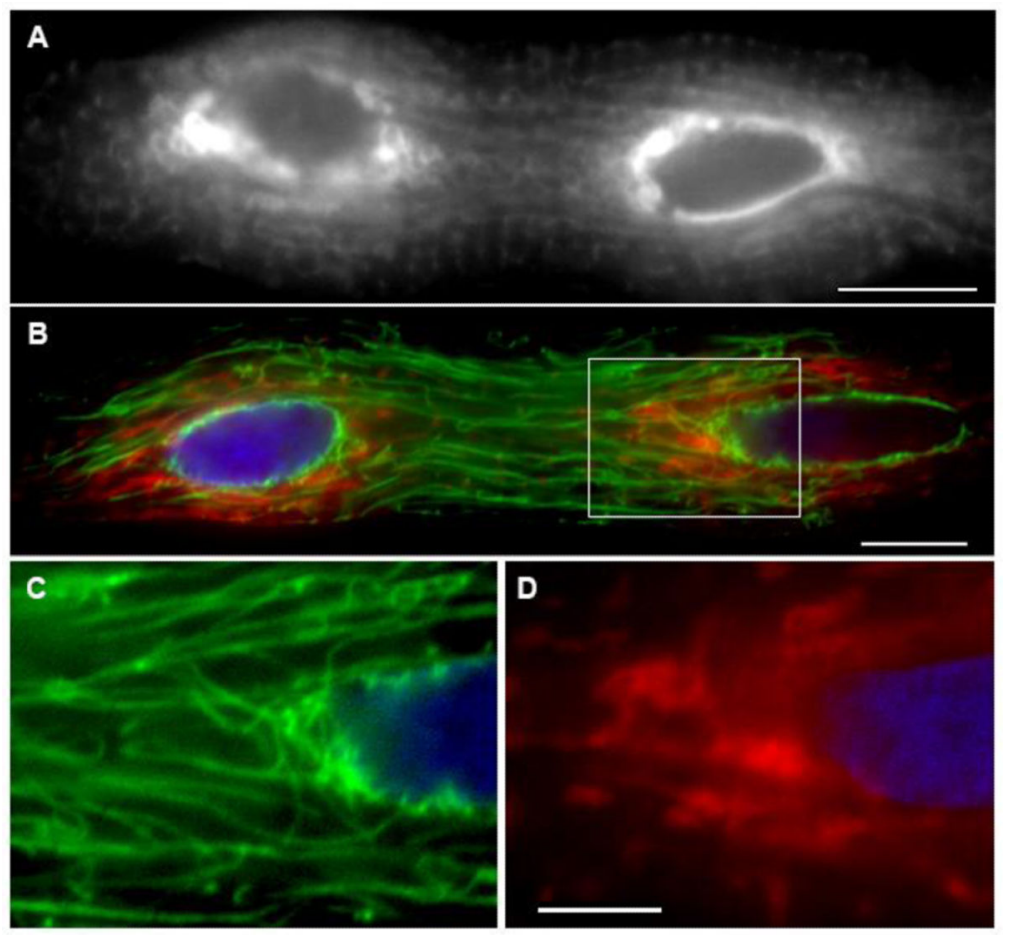

Fig. 6. CSQ2-DsRed-containing ER traffics between myonuclei in line with MTs Cardiomyocytes were cultured for $48 \mathrm{~h}$ with CSQ2-DsRed adenovirus, and fixed before immunostaining with anti-alpha tubulin (green). (A) CSQ2-DsRed fluorescence shows high levels of accumulation in juxtanuclear ER cisternae, but also within longitudinal tubules of ER extending between the two nuclei. (B) Double labeling of CSQ2-DsRed (red) and alpha tubulin immunofluorescence shows abundant MTs extending between nuclei. Anti-tubulin immunofluorescence $(\mathbf{C})$ of the panel B inset shows a complex scaffold that might support ER tubules containing CSQ2-DsRed (D). Scale bar, $10 \mu \mathrm{M}, \mathrm{A}, \mathrm{B} ; 5 \mu \mathrm{M}, \mathrm{D}$. 


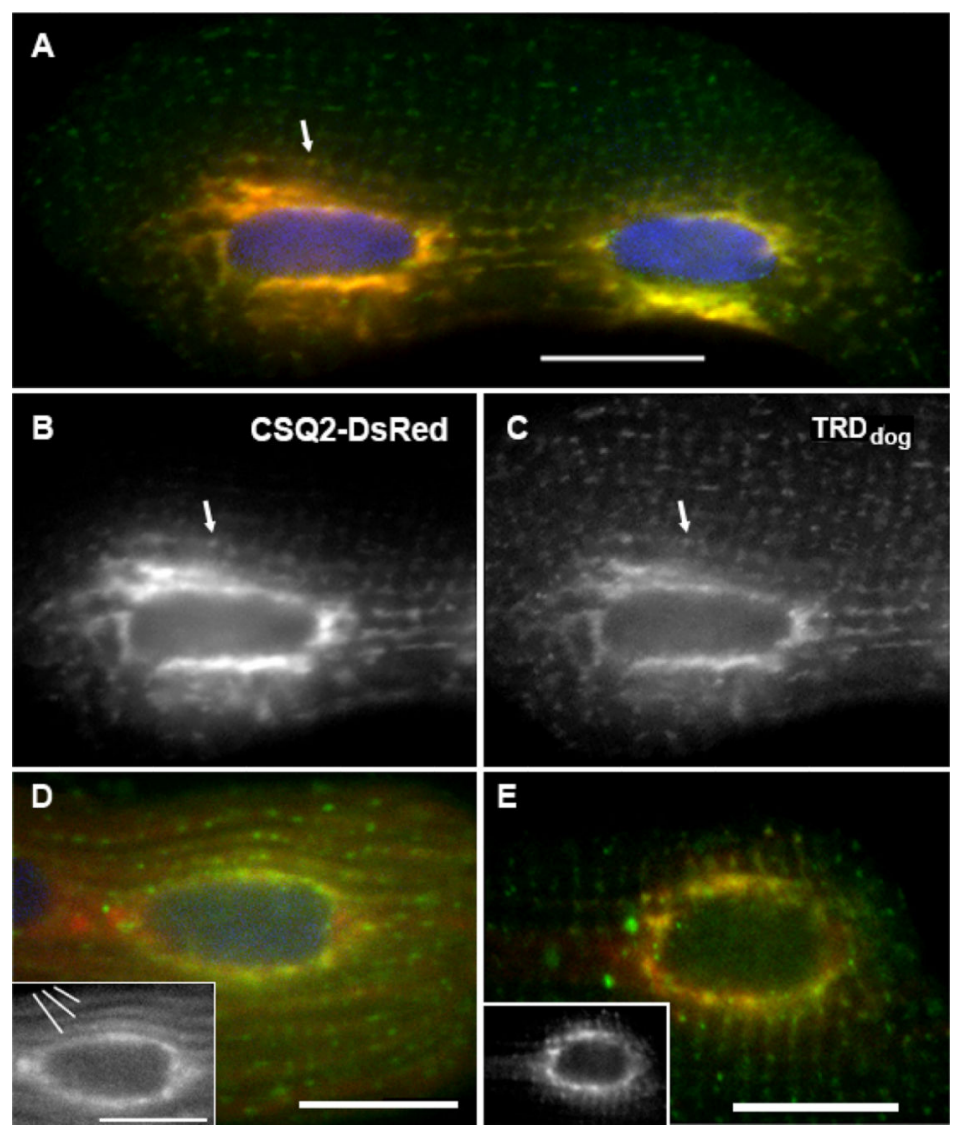

Fig. 7. TRD $_{\text {dog }}$ labels jSR sites early, but later becomes retained in ER by binding to polymerized CSQ2-DsRed

Cardiomyocytes were cultured with adenoviruses encoding CSQ2-DsRed and TRD $\mathrm{dog}_{\text {for }}$

36-48 h, which led to co-localized protein accumulation around and between myonuclei. (A)

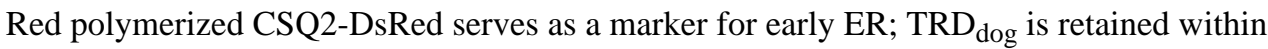
this series of smooth ER membranes, depending upon the rates of $\mathrm{TRD}_{\mathrm{dog}}$ synthesis and trafficking. Although uncommon, some cells appeared to contain jSR puncta that contained CSQ2-DsRed and TRD ${ }_{\text {dog }}($ arrows). $(\mathbf{B}, \mathbf{C})$ Individual color channels for CSQ2-DsRed (red channel) or $\mathrm{TRD}_{\mathrm{dog}}$ (green channel) are shown in black and white. (D) At $36 \mathrm{~h}$ of expression, CSQ2-DsRed was localized in rough ER and in longitudinal tracks of ER encircling the cell (white lines in inset). JSR puncta (green) aligned along the same smooth ER tracts, but CSQ2-DsRed remained a non-punctate ER marker (inset). This suggests that longitudinal ER traffic is not obligated to become jSR. (E) CSQ2-DsRed also formed bright puncta in rough ER that projected smoothly in a transverse direction without entering jSR (green). Scale bar, $10 \mu \mathrm{M}, \mathrm{A}-\mathrm{C} ; 5 \mu \mathrm{M}, \mathrm{D}, \mathrm{E}$. 

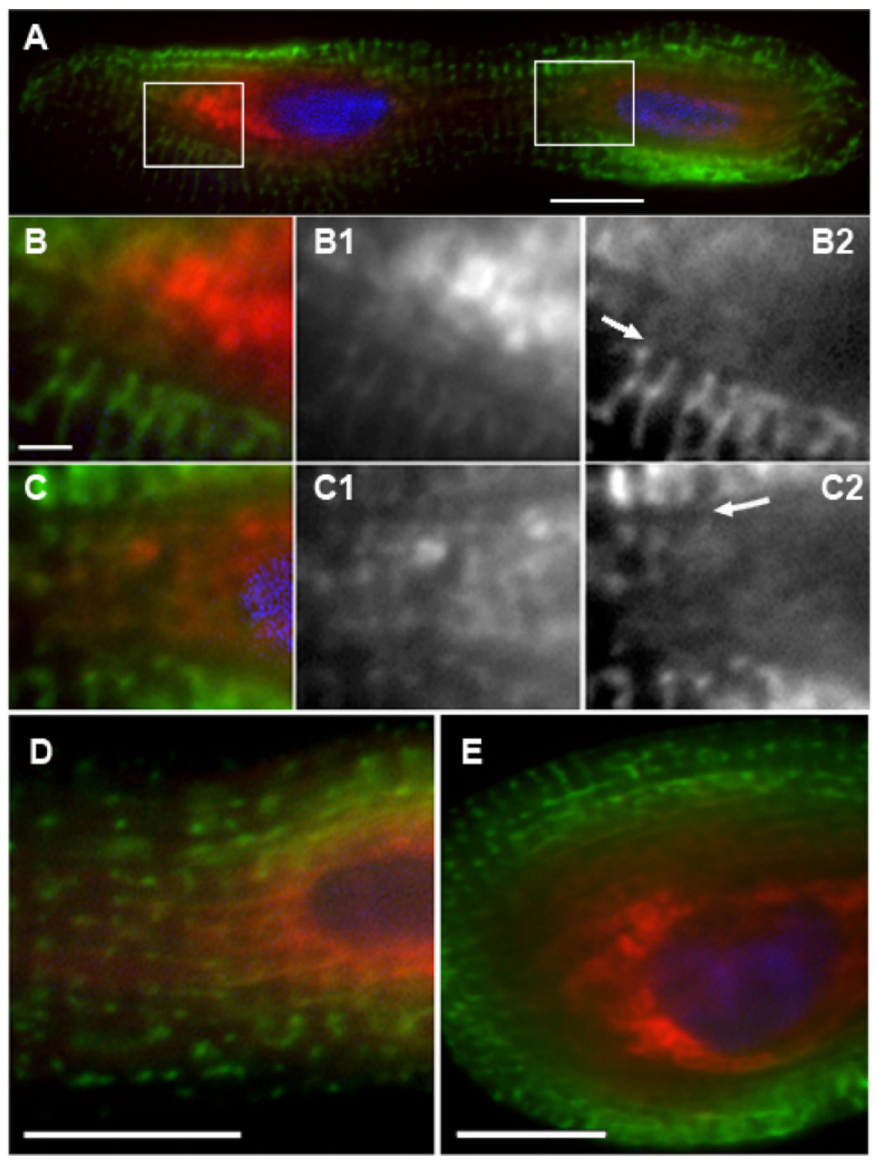

Fig. 8. ${ }^{\text {del }}$ TRD labels jSR, and highlights the transition from CSQ2-DsRed containing smooth ER

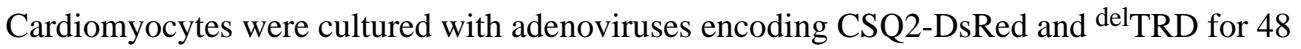
h. (A) CSQ2-DsRed fluorescence surrounds each myonuclei, but little overlap is seen with

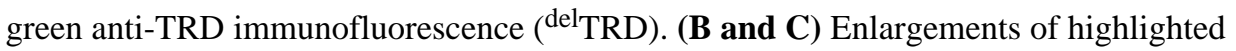
areas of the two perinuclear regions are shown as individual channels for CSQ2-DsRed

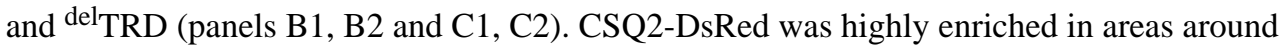
and between nuclei, and greatly reduced in more distal ER/SR compartments (panels B1 and C1). $\mathrm{TRD}_{\mathrm{dog}}$ immunofluorescence (panels B2 and C2) shows the opposite effect: reduced immunofluorescence in CSQ2-DsRed compartments (smooth ER), with concentrated jSR puncta originating in tubules outside of the perimeter of ER defined by CSQ2-DsRed.

Arrows indicate ER-SR transition areas. (D) $\mathrm{TRD}_{\mathrm{dog}}$ after $36 \mathrm{~h}$ expression is present in the smooth ER compartments as it develops its jSR enrichment. (E) By 48 h, smooth ER becomes expanded by CSQ2-DsRed and the transition to jSR puncta moves further away from the nucleus. 


\section{A}

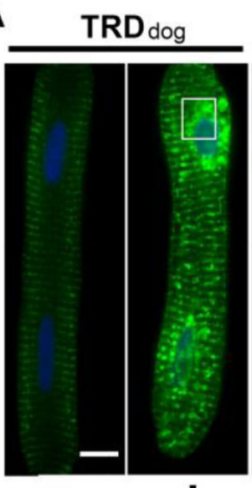

$=$

C

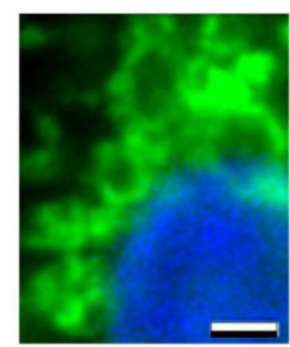

$\mathrm{JCT} \operatorname{dog}$

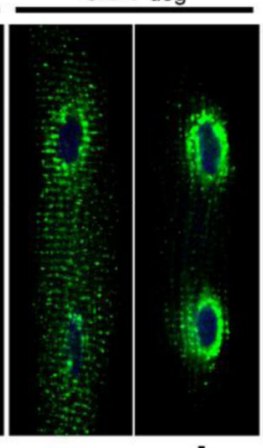

$\mathrm{TRD}_{\operatorname{dog}}+\mathrm{JCT} \mathrm{T}_{\text {dog }}$
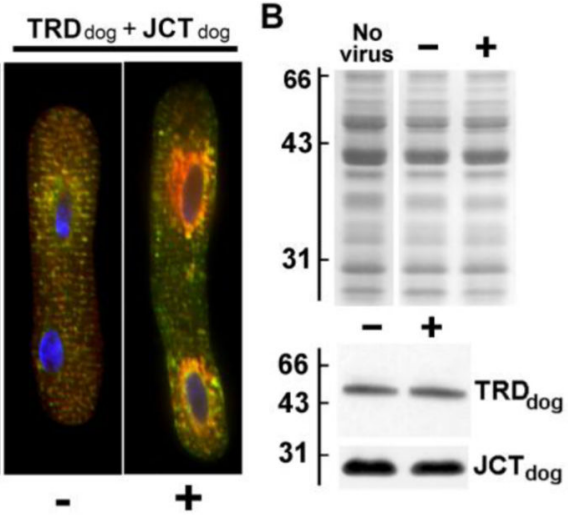

D

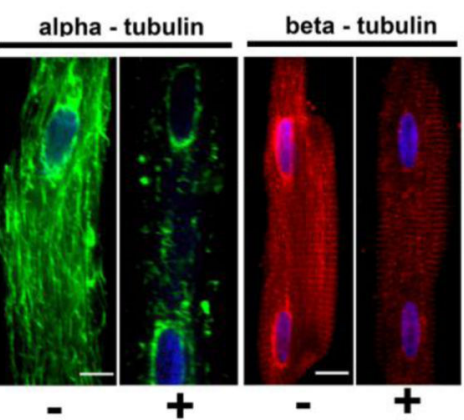

Fig. 9. Nocodazole treatment prevents anterograde movement of jSR proteins Immunofluorescence of cardiomyocytes untreated $(-)$ or treated $(+)$ with nocodazole $(20$ $\mu \mathrm{M})$ for $36 \mathrm{~h}$. Nocodazole was added $16 \mathrm{~h}$ after plating and virus additions. (A) Cells were treated with Ad.TRD $D_{\text {dog }}$ and stained with anti-TRD $D_{\text {dog }}$ (green); or, treated with Ad.JCT $T_{\text {dog }}$ and stained with anti-JCT $\mathrm{Jog}_{\mathrm{d}}$ (green), or treated with both viruses. (B) Amido black-stained nitrocellulose (upper half) and immunoblot data for anti-TRD $\mathrm{dog}_{\text {or }}$ anti-JCT $\mathrm{Jog}_{\mathrm{do}}$ immunoreactivity after $48 \mathrm{~h}$ of culture in the absence (-) or presence of nocodazole (20 $\mu \mathrm{M})$ for $36 \mathrm{~h}$. Molecular weight markers (in kDa) are indicated on the left. (C) Magnification of outlined box from panel $A$ showing juxtanuclear accumulations of $\mathrm{TRD}_{\mathrm{dog}}$ caused by nocodazole treatment. (D) Effect of nocodazole treatment on MTs visualized using antibodies against either alpha-tubulin (green) or beta-tubulin (red). Scale bar, $10 \mu \mathrm{M}$ in panels $\mathrm{A}$ and $\mathrm{C} ; 2 \mu \mathrm{M}$ in $\mathrm{B}$. 


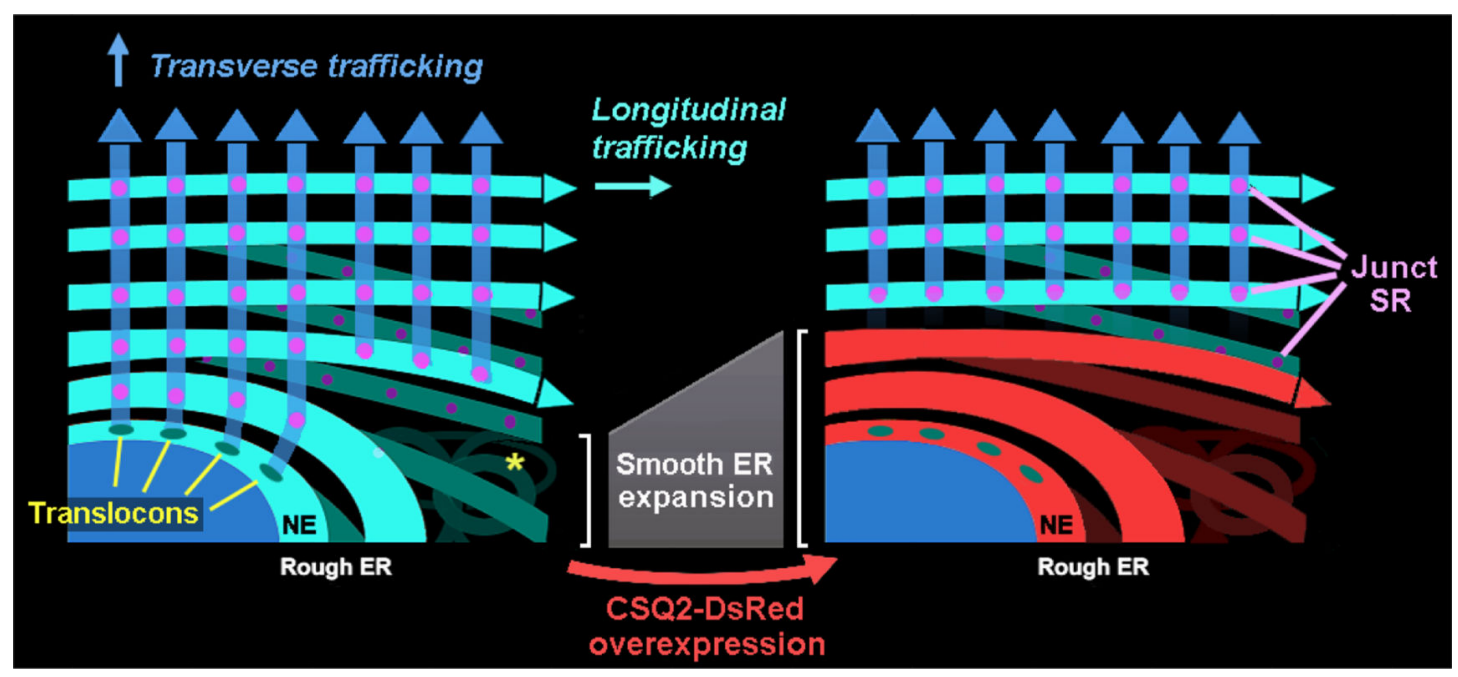

Fig. 10. Model of trafficking of newly-made jSR proteins from cardiac rough ER and smooth ER Left panel, protein translation of JCT or TRD in cultured primary adult normal cardiomyocytes occurs in the nuclear envelope (NE). Areas exist within the NE (green ellipses) in which translocon complexes are aligned with sarcomeres to transport ER containing JCT and TRD proteins transversely (radially) along a set of Z-tubules (Transverse trafficking, vertical blue arrows) directly to jSR (Junct SR, pink circles). Rough ER becomes tubules of longitudinally (axially) aligned smooth ER (Longitudinal trafficking, curved and longitudinal turquoise arrows) that can generate additional sites of transverse trafficking to jSR, and might also directly populate jSR puncta. Convoluted sets of ER tubules occupy an axis between nuclei (asterisk, *). Right panel, following high levels of CSQ2-DsRed expression and its accumulation in smooth ER, transitions to jSR sites no longer occur effectively, leading to a changes in ER and SR membrane partitioning (central gray fill). Solid blue and turquoise arrows are schematic only, representing membrane traffic across multiple tubules and/or vesicles of ER. All ER organnelar traffic is thought to occur along MTs (not shown). 


\section{Table I}

Relative selectivity of jSR protein antibodies for dog or rat forms.

\begin{tabular}{ccccc}
\hline \multirow{2}{*}{ Protein Target } & Antibody & Dog & Rat & \\
\hline TRD & anti-TRDdog & + & - & polyclonal \\
& anti-TRDrat & - & + & monoclonal \\
\hline \multirow{2}{*}{ JCT } & anti-JCTdog & ++ & - & monoclonal \\
& anti-JCTrat & + & ++ & polyclonal \\
\hline
\end{tabular}

